\title{
Potent and prolonged innate immune activation by enzyme-sensitive imidazoquinoline TLR7/8 agonist prodrug vesicles
}

Bi Wang ${ }^{\dagger}$, Simon Van Herck\#, Yong Chen\#, Xiangyang Bai†, Zifu Zhong§, Kim Deswarte^, Bart N. Lambrecht ${ }^{\wedge}$, Niek N. Sanders ${ }^{\S}$, Stefan Lienenklaus ${ }^{\Uparrow}$, Hans W. Scheeren ${ }^{\dagger}$, Sunil A. David $^{\&}$, Fabian Kiessling ${ }^{\dagger}$, Twan Lammers ${ }^{\dagger \notin *}$, Bruno G. De Geest ${ }^{\dagger *}$, Yang Shi ${ }^{\dagger *}$

$\dagger$ Institute for Experimental Molecular Imaging, Uniklinik RWTH Aachen and Helmholtz Institute for Biomedical Engineering, Faculty of Medicine, RWTH Aachen University, 52074 Aachen, Germany

\# Department of Pharmaceutics, Ghent University, Ghent, Belgium

$\S$ Laboratory of Gene Therapy, Ghent University, Ghent, Belgium

Department of Internal Medicine and Pediatrics, Ghent University, VIB Center for Inflammation Research, Ghent, Belgium.

${ }^{ \pm}$Department of Pulmonary Medicine, Erasmus University Medical Center, Rotterdam, The Netherlands

q Institute for Laboratory Animal Science and Institute of Immunology, Hanover Medical School, Hannover, Germany. \& Virovax, Lawrance (KS), United States

+ Department of Pharmaceutics, Utrecht University, 3584 CG Utrecht, The Netherlands

\& Department of Targeted Therapeutics, University of Twente, 7500 AE Enschede, The Netherlands

\section{Content}

1. Details of synthesis and characterizations

2. Preparation and characterizations of vesicles

3. Stability of nanoparticles based on PEG5/2/0.75k-GL2-IMDQ

4. Enzymatic degradation of vesicles

5. In vitro RAW Blue assay

6. Cellular uptake of $\mathrm{Cy} 3$

7. In vivo immunomodulation in luciferase reporter mice

8. In vivo dendritic cell recruitment and activation 


\section{Details of synthesis and characterizations}

\section{Materials.}

D-(+)-glucuronic acid $\gamma$-lactone (compound 1), sodium methoxide ( $\mathrm{NaOMe})$, pyridine, ammonium carbonate, methyl-(p-hydroxymethyl) benzoate (compound 5), imidazole, tertbutyldimethylsilyl chloride, triethylamine (TEA), diphenylphosphoryl azide (DPPA), lithium methoxide solution (LiOMe), propargyl alcohol, 4-nitrophenyl chloroformate $(\mathrm{Cl}-$ $\left.\mathrm{COOPh} \cdot \mathrm{NO}_{2}\right), \quad \mathrm{N}$-(3-dimethylaminopropyl)-N-ethylcarbodiimide hydrochloride $(\mathrm{EDC} \cdot \mathrm{HCl}), \mathrm{N}$-hydroxysuccinimide $(\mathrm{NHS})$, acetic anhydride $\left((\mathrm{AcO})_{2}\right)$, potassium bisulfate $\left(\mathrm{KHSO}_{4}\right)$, potassium hydroxide $(\mathrm{KOH})$, sodium bicarbonate $\left(\mathrm{NaHCO}_{3}\right)$, acetic acid, dichloromethane (DCM), acetonitrile $(\mathrm{ACN}), \mathrm{CuI}$ and sodium ascorbate, methanol, heptane, ethyl acetate, toluene, tetrahydrofuran (THF), dimethylformamide (DMF), dimethyl sulfoxide (DMSO), pentane were ordered from Sigma. COOH-PEG5k-OH was ordered from JenKem Technology. Sodium was purchased from abcr GmbH. Azidefunctionalized PEG was synthesized by modifying COOH-PEG-OH with 3-azido-1propanamine by EDC coupling. $\beta$-glucosidase ( $\beta$-GUS, $\geq 1,000$ units/mg) and esterase (from porcine liver, $\geq 15$ units/mg) were ordered from Sigma. IMDQ was synthesized according to literature. ${ }^{1}$ The Raw Blue reporter cell line were obtained from InvivoGen. DC 2.4 cell line was a kind gift from Dr. Kenneth Rock (University of Massachusetts, Boston, US). The luciferase reporter mice model (IFN $\beta+/ \Delta \beta-1$ uc) with a BALB/c background was provided by Dr. Stefan Lienenklaus. ${ }^{2}$

NMR analysis: ${ }^{1} \mathrm{H}-\mathrm{NMR}$ spectra of chemical were recorded on a Bruker $600 \mathrm{MHz}$ FT NMR spectrometer. Chemical shifts $(\delta)$ are provided in ppm relative to TMS. Samples were prepared in given deuterated solvents and the chemical shifts were referenced to residual nondeuterated signals of the solvent.

ESI-MS spectrometry was performed on a Waters LCT Premier XETM Time of flight (TOF) mass spectrometer, which was equipped with a standard electrospray ionization and modular LockSpray TM interface.

HPLC was performed on Agilent 1260 Infinity equipped with a Diode Array and Multiple Wavelength Detector using a reversed phase column (Eclipse Plus C8, 3.5 $\mu \mathrm{m}, 4.6^{*} 150 \mathrm{~mm}$ ). A gradient elution method was used with eluent A $(0.1 \%$ trifluoroacetic acid in ACN) increasing from $5 \%$ to $95 \%$ in 10 minutes (eluent $\mathrm{B}$ was $\mathrm{H}_{2} \mathrm{O}$ with $0.1 \%$ trifluoroacetic acid). The flow rate was $1 \mathrm{~mL} / \mathrm{min}$ and the detection wavelength was $254 \mathrm{~nm}$.

\section{Compound 4}

Compound 4 was synthesized by a published method with minor modifications $\mathrm{s}^{3,4}$.
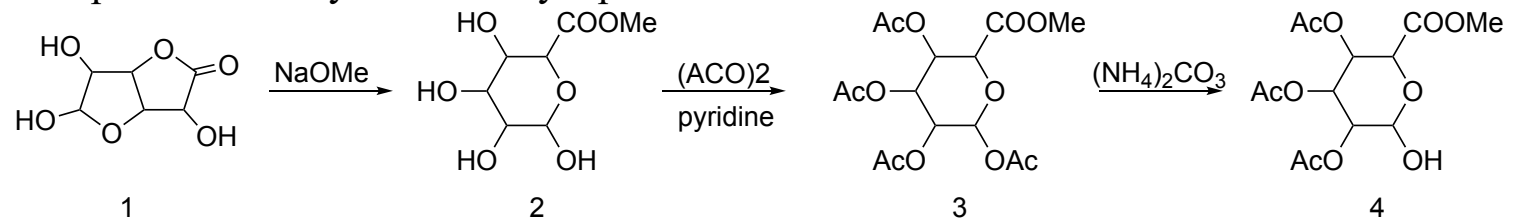


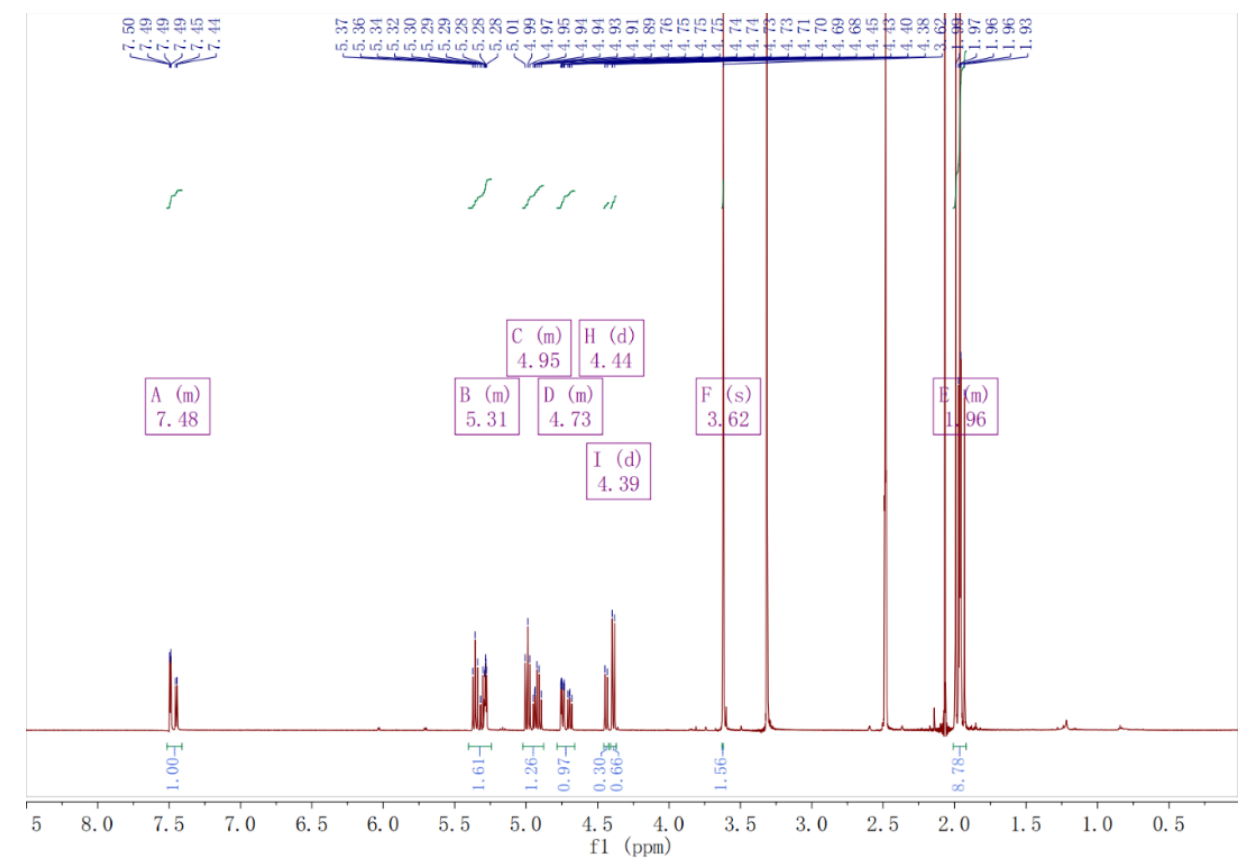

${ }^{1} \mathrm{H}$ NMR $\left(600 \mathrm{MHz}, \mathrm{DMSO}-d_{6}\right) \delta 7.51-7.41(\mathrm{~m}, 1 \mathrm{H},-\mathrm{OH}), 5.40-5.24(\mathrm{~m}, 2 \mathrm{H}$, Glu 1,3H), $5.02-4.88(\mathrm{~m}, 1 \mathrm{H}$, Glu 2-H), $4.78-4.66(\mathrm{~m}, 1 \mathrm{H}$, Glu 4-H), 4.39 (d, $J=10.1 \mathrm{~Hz}, 1 \mathrm{H}$, Glu 5-H), $3.62\left(\mathrm{~s}, 3 \mathrm{H}, \mathrm{COOCH}_{3}\right), 2.01-1.92(\mathrm{~m}, 9 \mathrm{H},-\mathrm{OAc})$.

\section{Compound 8}

Compound 8 was synthesized by a reported method ${ }^{5}$.

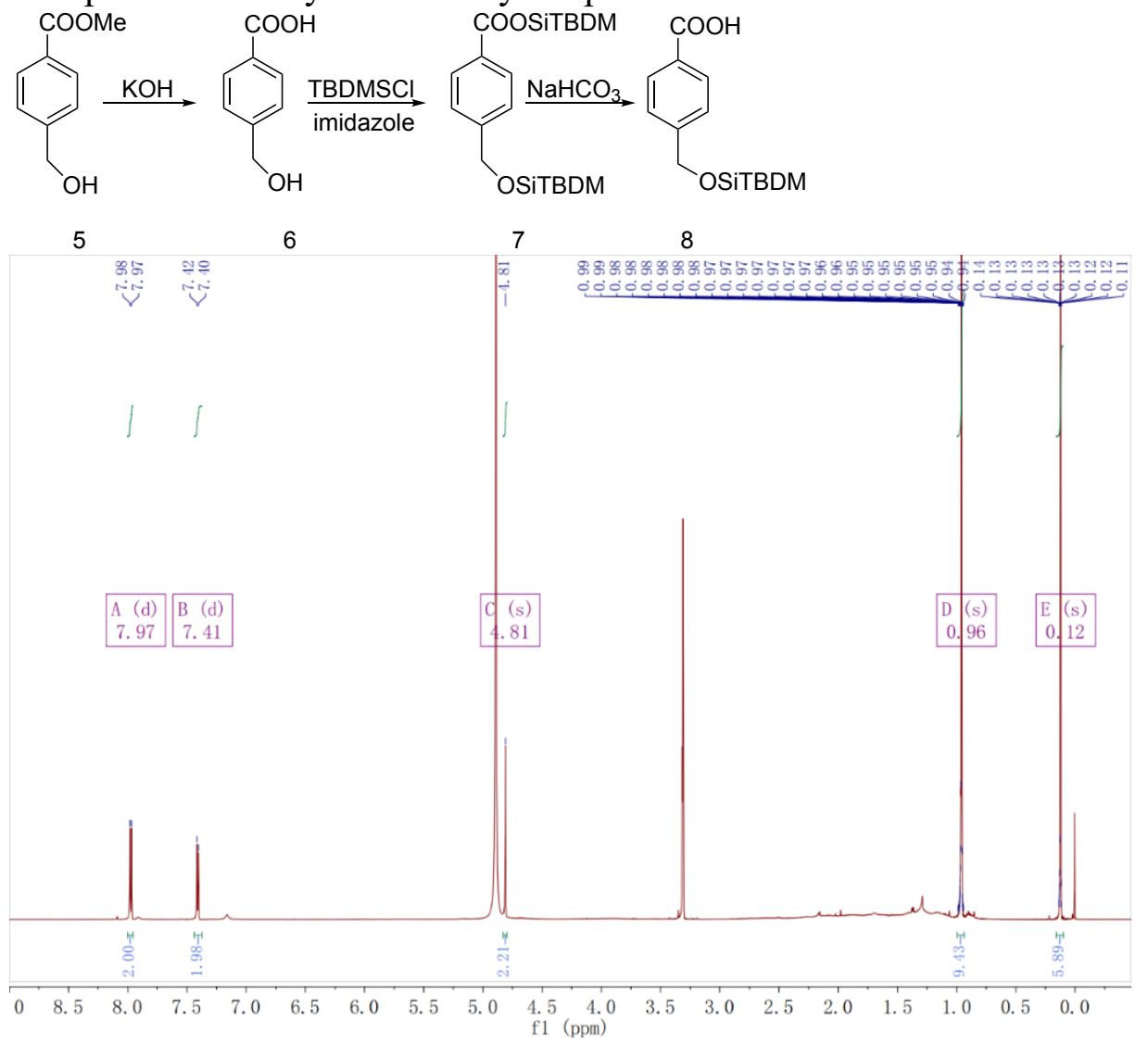


${ }^{1} \mathrm{H}$ NMR (600 MHz, Methanol- $\left.d_{4}\right) \delta 7.97$ (d, $\left.J=8.2 \mathrm{~Hz}, 2 \mathrm{H}, \mathrm{Ar}\right), 7.41$ (d, $J=8.3 \mathrm{~Hz}, 2 \mathrm{H}$, Ar), 4.81 (s, 2H, Ar-CH $), 0.96$ (s, 9H, Si-tBut), 0.12 (s, 6H, Si-Me $\mathrm{Me}_{2}$.

\section{Compound 9}

Firstly, the carboxylic acid of 8 was converted to isocyanate. Generally, $2 \mathrm{~g}$ (7.52 mmol) of $8,0.9 \mathrm{~g}(8.9 \mathrm{mmol})$ of triethylamine (TEA) and $2.45 \mathrm{~g}(8.9 \mathrm{mmol})$ of diphenylphosphoryl azide (DPPA) were dissolved in $40 \mathrm{~mL}$ of dry toluene under argon atmosphere at $85{ }^{\circ} \mathrm{C}$ under stirring for 3 hours. Afterwards, $2 \mathrm{~g}$ of $4(6 \mathrm{mmol})$ in $20 \mathrm{~mL}$ of toluene was added to the above mixture and the reaction was left overnight at room temperature under stirring. The solvent was removed using a rotary evaporator and the residue was purified by column chromatography (heptane/ ethyl acetate $=5 / 2$ ). Yield: $80.8 \%$.

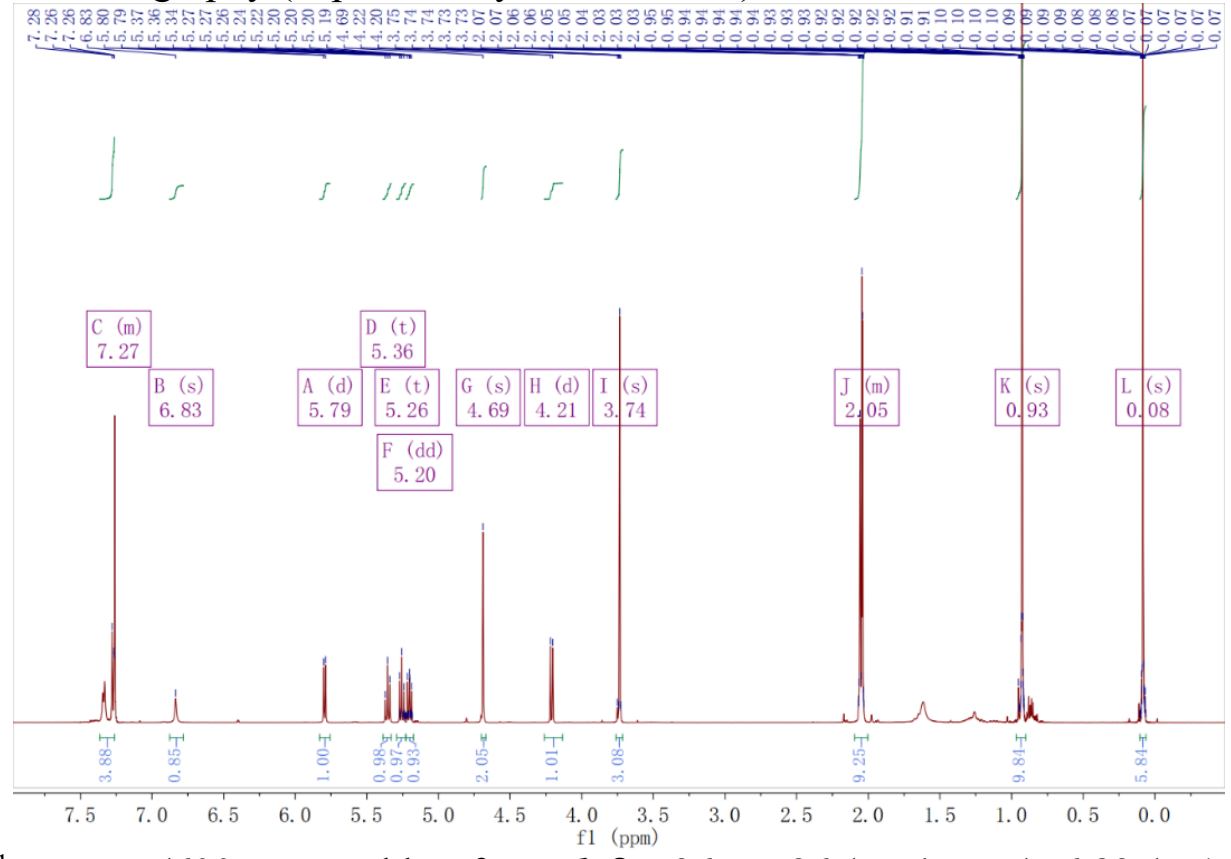

${ }^{1} \mathrm{H}$ NMR (600 MHz, Chloroform- $d$ ) $\delta 7.36-7.26$ (m, 4H, Ar), 6.83 (s, 1H, NH), 5.79 (d, $J=8.0 \mathrm{~Hz}, 1 \mathrm{H}$, Glu 1-H), $5.36(\mathrm{t}, J=9.4 \mathrm{~Hz}, 1 \mathrm{H}$, Glu 2-H), $5.26(\mathrm{t}, J=9.6 \mathrm{~Hz}, 1 \mathrm{H}$, Glu $3-$ H), $5.20(\mathrm{dd}, J=9.3 \mathrm{~Hz}, 1 \mathrm{H}$, Glu 4-H), 4.69 (s, 2H, Ar-CH $), 4.21(\mathrm{~d}, J=9.8 \mathrm{~Hz}, 1 \mathrm{H}$, Glu 5-H), 3.74 (s, 3H, $\left.\mathrm{COOCH}_{3}\right), 2.10-2.01$ (m, 9H, OAc), 0.93 (s, 9H, Si-tBut), 0.08 (s, 6H, $\left.\mathrm{Si}-\mathrm{Me}_{2}\right)$.

\section{Compound 10}

$7.3 \mathrm{~g}$ of 9 was hydrolyzed in $180 \mathrm{~mL}$ of water/THF/acetic acid (1/1/1, v/v/v) for 4 hours. The mixture was concentrated and the residue was dissolved in dichloromethane and purified by column chromatography (heptane/ethyl acetate $=2 / 3$ ). Yield: $97.5 \%$. 


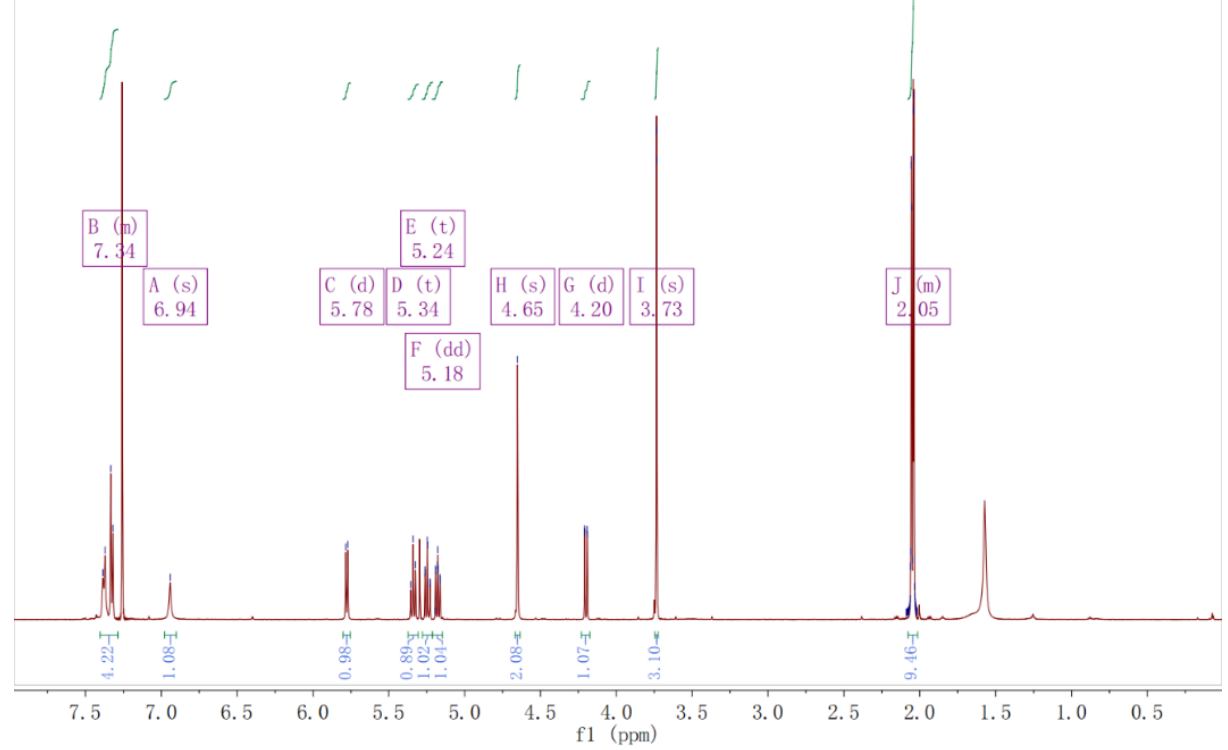

${ }^{1} \mathrm{H}$ NMR (600 MHz, Chloroform-d) $\delta 7.40-7.28$ (m, 4H, Ar), 6.94 (s, 1H, NH), 5.78 (d, $J=8.0 \mathrm{~Hz}, 1 \mathrm{H}$, Glu 1-H), $5.34(\mathrm{t}, J=9.4 \mathrm{~Hz}, 1 \mathrm{H}$, Glu 2-H), $5.24(\mathrm{t}, J=9.6 \mathrm{~Hz}, 1 \mathrm{H}$, Glu 3H), $5.18\left(\mathrm{dd}, J=9.1 \mathrm{~Hz}, 1 \mathrm{H}\right.$, Glu 4-H), $4.65\left(\mathrm{~s}, 2 \mathrm{H}, \mathrm{Ar}-\mathrm{CH}_{2}\right), 4.20(\mathrm{~d}, J=9.8 \mathrm{~Hz}, 1 \mathrm{H}$, Glu 5-H), $3.73\left(\mathrm{~s}, 3 \mathrm{H}, \mathrm{COOCH}_{3}\right), 2.08-2.02(\mathrm{~m}, 9 \mathrm{H}, \mathrm{OAc})$.

\section{Compound 11}

The procedure to synthesize 11 was similar as that for 9 . Firstly, the carboxylic acid of 8 $(5.3 \mathrm{mmol})$ was converted to isocyanate, to which $2 \mathrm{~g}$ of $10(4.1 \mathrm{mmol})$ and $0.42 \mathrm{~g}$ of triethylamine (TEA, $4.1 \mathrm{mmol}$ ) dissolved in $15 \mathrm{~mL}$ dried toluene and $10 \mathrm{~mL}$ acetonitrile was added. The reaction was conducted overnight at room temperature. The reaction mixture was dried and brought on a silica column (heptane/ ethyl acetate $=2 / 1$ ) to isolate 11. Yield: $52.1 \%$. 


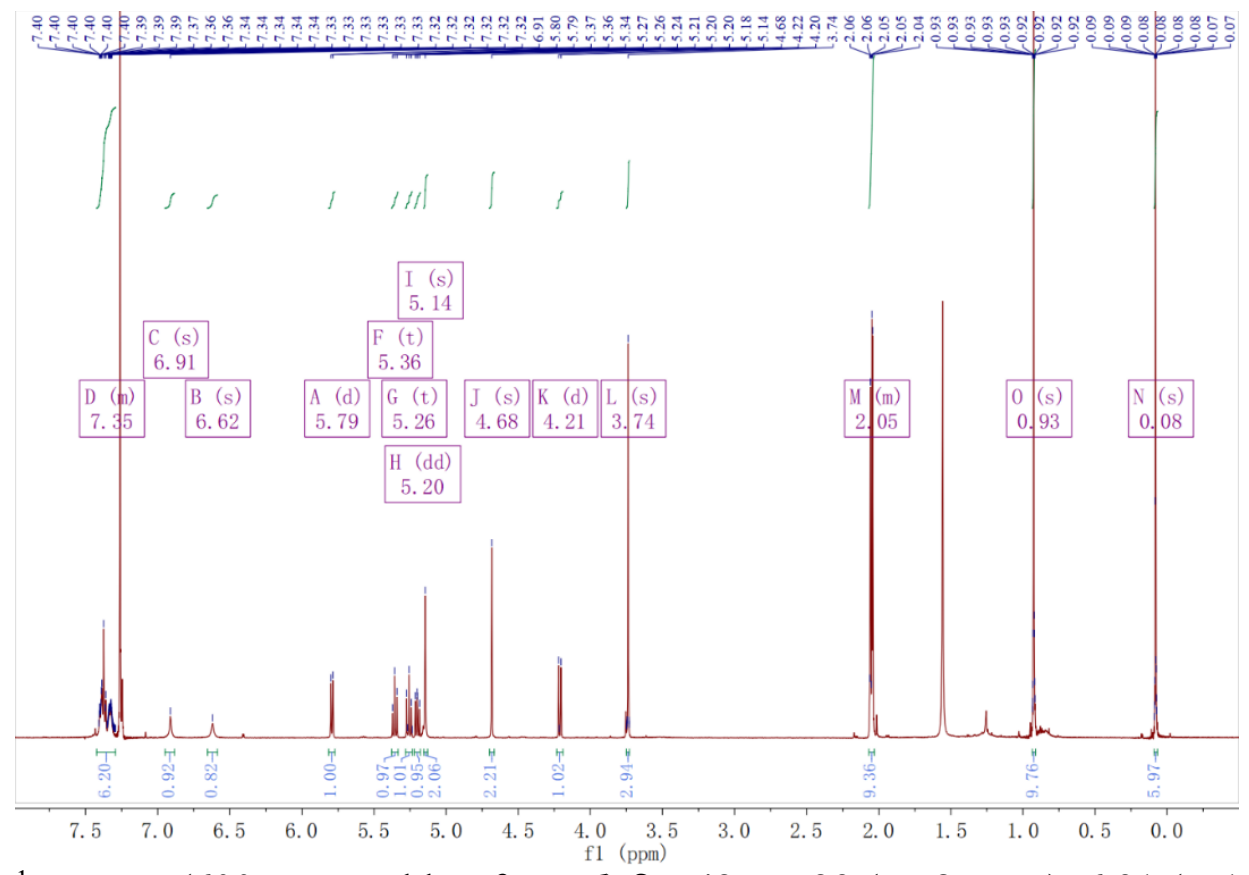

${ }^{1} \mathrm{H}$ NMR (600 MHz, Chloroform- $d$ ) $\delta 7.42-7.29$ (m, 8H, Ar), 6.91 (s, 1H, NH), 6.62 (s, $1 \mathrm{H}, \mathrm{NH}), 5.79$ (d, $J=8.0 \mathrm{~Hz}, 1 \mathrm{H}$, Glu 1-H), 5.36 (t, $J=9.4 \mathrm{~Hz}, 1 \mathrm{H}$, Glu 2-H), 5.26 (t, $J=$ $9.6 \mathrm{~Hz}, 1 \mathrm{H}$, Glu 3-H), 5.20 (dd, $J=9.3 \mathrm{~Hz}, 1 \mathrm{H}$, Glu 4-H), 5.14 (s, 2H, Ar-CH $), 4.68$ (s, $\left.2 \mathrm{H}, \mathrm{Ar}_{-} \mathrm{CH}_{2}\right), 4.21\left(\mathrm{~d}, J=9.8 \mathrm{~Hz}, 1 \mathrm{H}\right.$, Glu 5-H), $3.74\left(\mathrm{~s}, 3 \mathrm{H}, \mathrm{COOCH}_{3}\right), 2.07-2.03$ (m, 9H, OAc), 0.93 (s, 9H, Si-tBut), 0.08 (s, 6H, Si-Mer).

\section{Compound 12}

12 was synthesized using a similar protocol as 10.11 (4 mmol) was dissolved in $45 \mathrm{~mL}$ of $\mathrm{THF} / \mathrm{H}_{2} \mathrm{O} /$ acetic acid $(1 / 1 / 1, \mathrm{v} / \mathrm{v} / \mathrm{v})$ and stirred for 4 hours. The reaction mixture was concentrated and 12 was purified by column chromatography (heptane/ethyl acetate $=2 / 3$ ). Yield: $98.6 \%$.

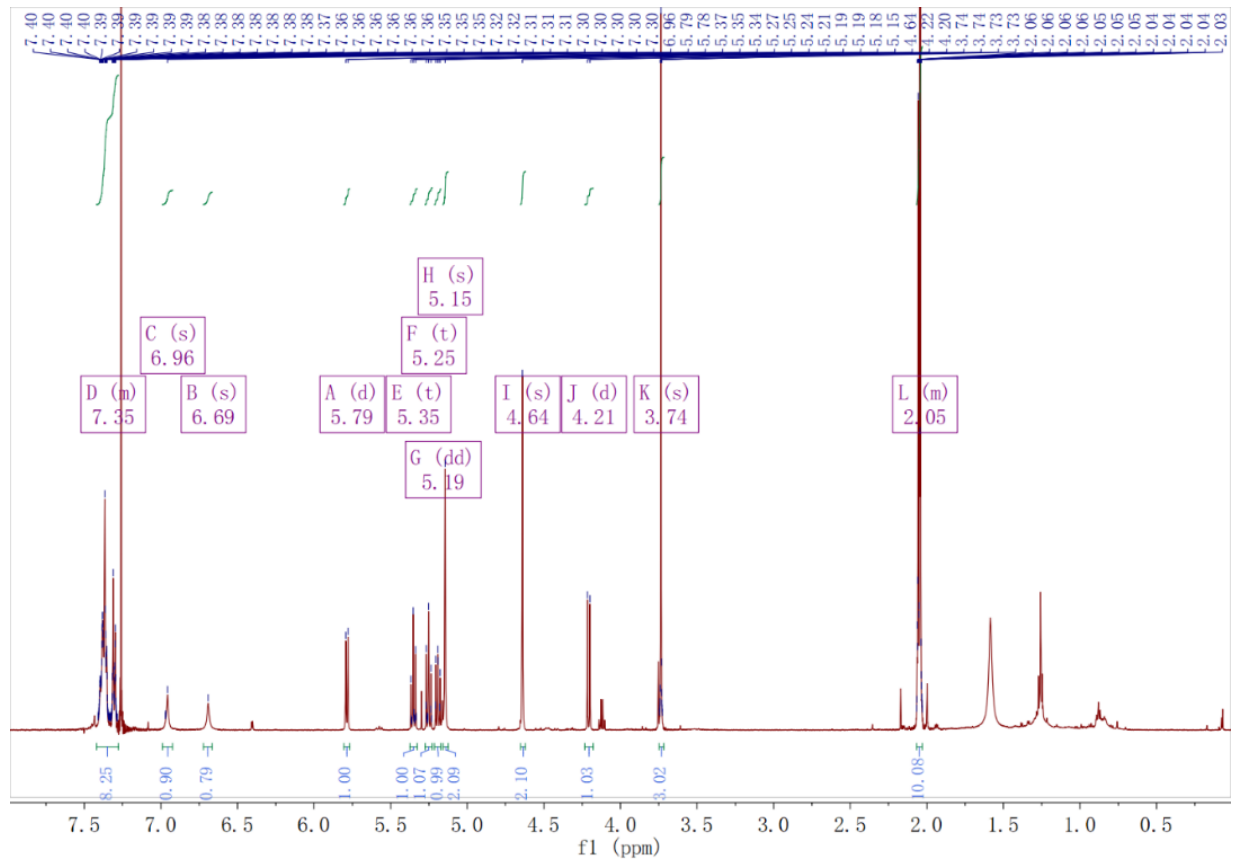


${ }^{1} \mathrm{H}$ NMR (600 MHz, Chloroform- $d$ ) $\delta 7.42-7.28$ (m, 8H, Ar), 6.96 (s, 1H, NH), 6.69 (s, $1 \mathrm{H}, \mathrm{NH}), 5.79$ (d, $J=8.0 \mathrm{~Hz}, 1 \mathrm{H}$, Glu 1-H), 5.35 (t, $J=9.4 \mathrm{~Hz}, 1 \mathrm{H}$, Glu 2-H), 5.25 (t, $J=$ $9.6 \mathrm{~Hz}, 1 \mathrm{H}$, Glu 3-H), 5.19 (dd, $J=9.3 \mathrm{~Hz}, 1 \mathrm{H}$, Glu 4-H), 5.15 (s, 2H, Ar-CH $), 4.64$ (s, $\left.2 \mathrm{H}, \mathrm{Ar}-\mathrm{CH}_{2}\right), 4.21$ (d, $J=9.8 \mathrm{~Hz}, 1 \mathrm{H}$, Glu 5-H) , 3.74 (s, 3H, $\left.\mathrm{COOCH}_{3}\right), 2.07-2.03$ (m, 9H, OAc).

\section{Compound 13}

13 was synthesized using a similar protocol as 9 and 11. The carboxylic acid group of compound $8(4.1 \mathrm{mmol})$ was converted to isocyanate at $85{ }^{\circ} \mathrm{C}$ under argon atmosphere. Afterwards, $2 \mathrm{~g}$ of $12(3.2 \mathrm{mmol})$ and $0.33 \mathrm{~g}$ of triethylamine (TEA, $3.2 \mathrm{mmol})$ dissolved in $12 \mathrm{~mL}$ dried toluene and $8 \mathrm{ml}$ acetonitrile was added to the above mixture. After overnight reaction at room temperature, the crude mixture was concentrated and the residue was dissolved in chloroform and purified by a silica column (heptane/ethyl acetate $=3 / 2$ ). Yield: $72.5 \%$.

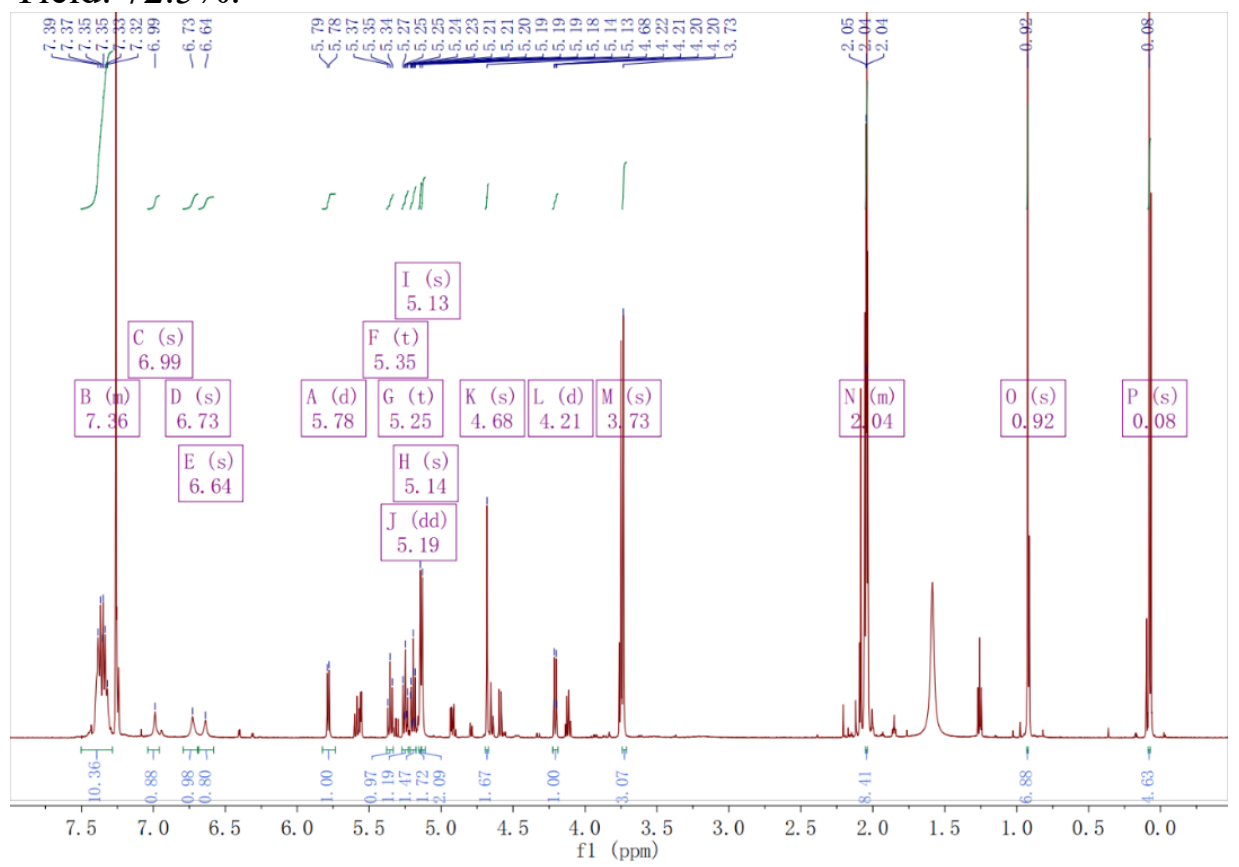

${ }^{1} \mathrm{H}$ NMR (600 MHz, Chloroform- $d$ ) $\delta 7.43-7.28$ (m, 12H, Ar), 6.99 (s, 1H, NH), 6.73 (s, $1 \mathrm{H}, \mathrm{NH}), 6.64(\mathrm{~s}, 1 \mathrm{H}, \mathrm{NH}), 5.78(\mathrm{~d}, J=8.0 \mathrm{~Hz}, 1 \mathrm{H}$, Glu 1-H), 5.35 (t, $J=9.4 \mathrm{~Hz}, 1 \mathrm{H}$, Glu 2-H), 5.25 (t, $J=9.7 \mathrm{~Hz}, 1 \mathrm{H}$, Glu 3-H), 5.19 (dd, $J=9.3 \mathrm{~Hz}, 1 \mathrm{H}$, Glu 4-H), 5.14 (s, 2H, Ar- $\left.\mathrm{CH}_{2}\right), 5.13\left(\mathrm{~s}, 2 \mathrm{H}, \mathrm{Ar}-\mathrm{CH}_{2}\right), 4.68\left(\mathrm{~s}, 2 \mathrm{H}, \mathrm{Ar}-\mathrm{CH}_{2}\right), 4.21$ (d, J=9.9 Hz, 1H, Glu 5-H), $3.73\left(\mathrm{~s}, 3 \mathrm{H}, \mathrm{COOCH}_{3}\right), 2.08-2.02$ (m, 9H, OAc), 0.92 (s, 9H, Si-tBut), 0.08 (s, 6H, Si$\left.\mathrm{Me}_{2}\right)$. 


\section{Compound 14}

14 was synthesized and purified using similar protocols as 10 and 12 . Yield: $33.8 \%$

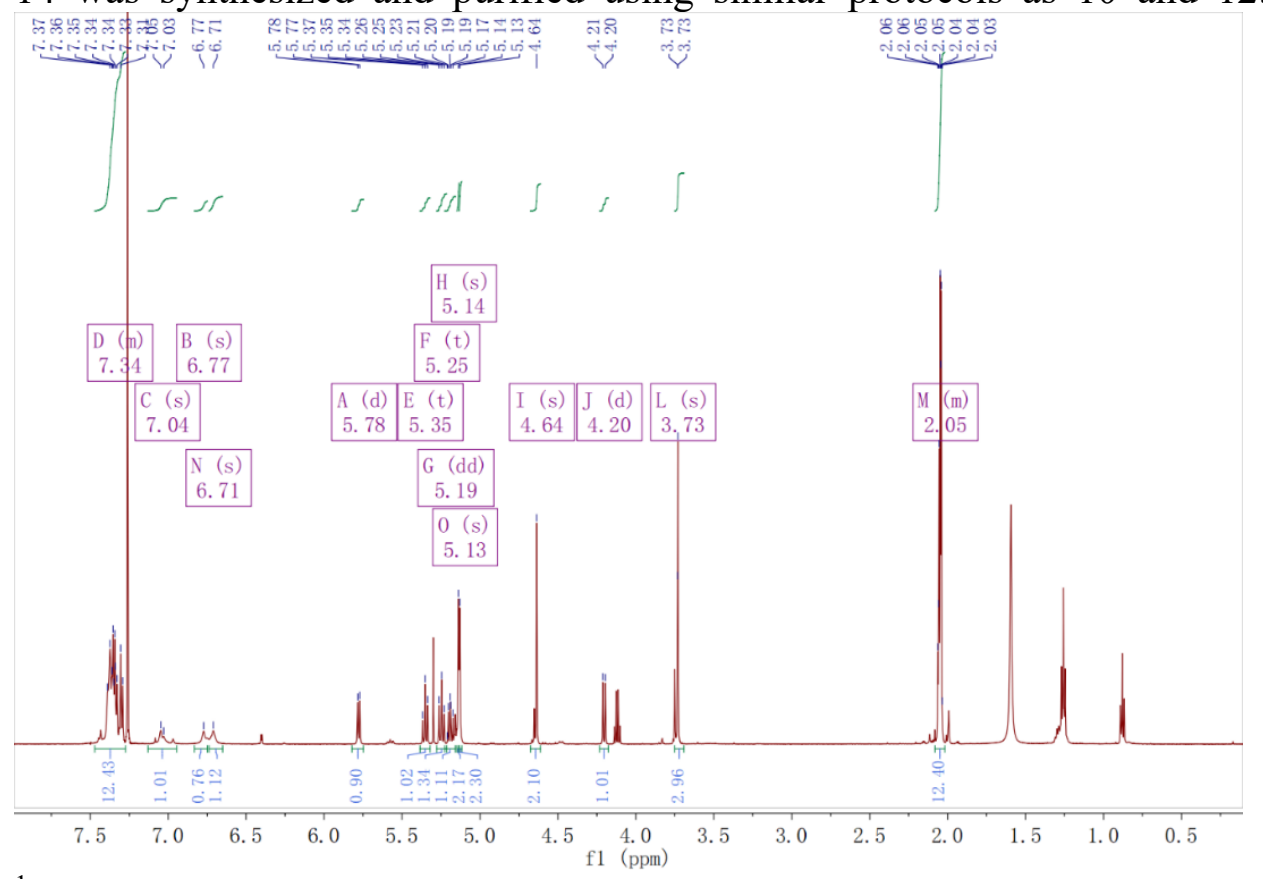

${ }^{1} \mathrm{H}$ NMR (600 MHz, Chloroform- $d$ ) $\delta 7.47-7.27$ (m, 12H, Ar), 7.04 (s, 1H, NH), 6.77 (s, $1 \mathrm{H}, \mathrm{NH}), 6.71(\mathrm{~s}, 1 \mathrm{H}, \mathrm{NH}), 5.78(\mathrm{~d}, J=8.1 \mathrm{~Hz}, 1 \mathrm{H}$, Glu 1-H), $5.35(\mathrm{t}, J=9.4 \mathrm{~Hz}, 1 \mathrm{H}$, Glu 2-H), 5.25 (t, $J=9.6 \mathrm{~Hz}, 1 \mathrm{H}$, Glu 3-H), 5.19 (dd, $J=9.3 \mathrm{~Hz}, 1 \mathrm{H}$, Glu 4-H), 5.14 (s, 2H, Ar- $\left.\mathrm{CH}_{2}\right), 5.13$ (s, 2H, Ar- $\left.\mathrm{CH}_{2}\right), 4.64\left(\mathrm{~s}, 2 \mathrm{H}, \mathrm{Ar}-\mathrm{CH}_{2}\right), 4.20$ (d, J=9.9 Hz, 1H, Glu 5-H), $3.73\left(\mathrm{~s}, 3 \mathrm{H}, \mathrm{COOCH}_{3}\right), 2.08-2.02(\mathrm{~m}, 9 \mathrm{H}, \mathrm{OAc})$.

\section{Compound 15-1,2,3}

$4.1 \mathrm{mmol}$ of 10,12 or 14 was dissolved in $50 \mathrm{ml}$ of $\mathrm{MeOH}$ and $45 \mathrm{~mL}$ of MeOH containing $4.6 \mathrm{ml} 1 \mathrm{M}$ LiOMe was added dropwise to the solution. After stirring for 2 hours at $0{ }^{\circ} \mathrm{C}$, the reaction mixture was neutralized with silica. The mixture was filtered and concentrated, and then was purified by column chromatography ( $2 \%$ methanol/ethyl acetate followed by $4 \%$ methanol/ethyl acetate). Yield of 15-1,2,3: 51.9, 73.5, and 25.6\%. 


\section{Compound 15-1}

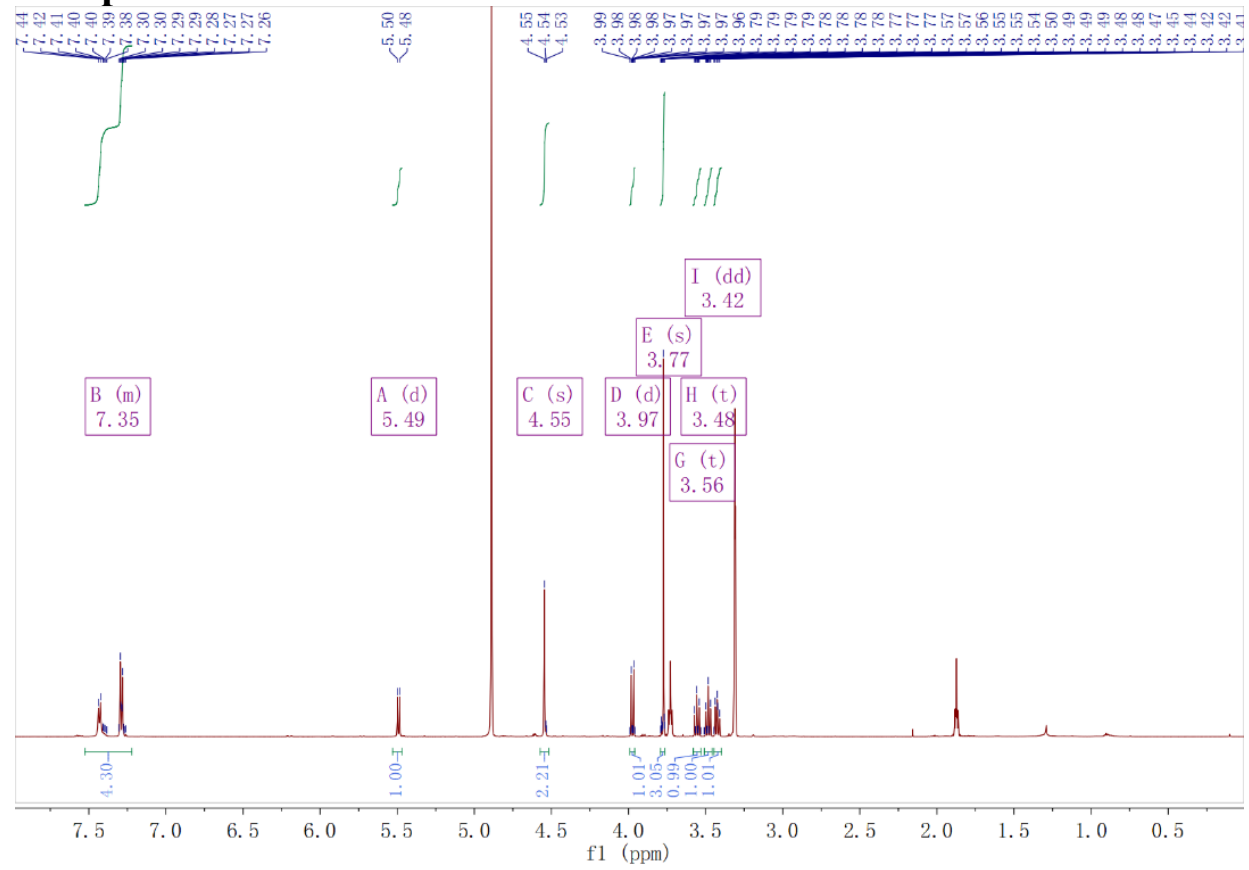

${ }^{1} \mathrm{H}$ NMR (600 MHz, Methanol- $\left.d_{4}\right) \delta 7.53-7.22(\mathrm{~m}, 4 \mathrm{H}, \mathrm{Ar}), 5.49(\mathrm{~d}, J=8.0 \mathrm{~Hz}, 1 \mathrm{H}$, Glu 1-H), 4.55 (s, 2H, Ar-CH $)_{2}, 3.97$ (d, $J=9.7 \mathrm{~Hz}, 1 \mathrm{H}$, Glu 5-H), 3.77 (s, $\left.3 \mathrm{H}, \mathrm{COOCH}_{3}\right), 3.56$ (t, $J=9.3 \mathrm{~Hz}, 1 \mathrm{H}$, Glu 2-H), 3.48 (t, $J=9.1 \mathrm{~Hz}, 1 \mathrm{H}$, Glu 3-H), 3.42 (dd, $J=9.1 \mathrm{~Hz}, 1 \mathrm{H}$, Glu 4-H).

\section{Compound 15-2}

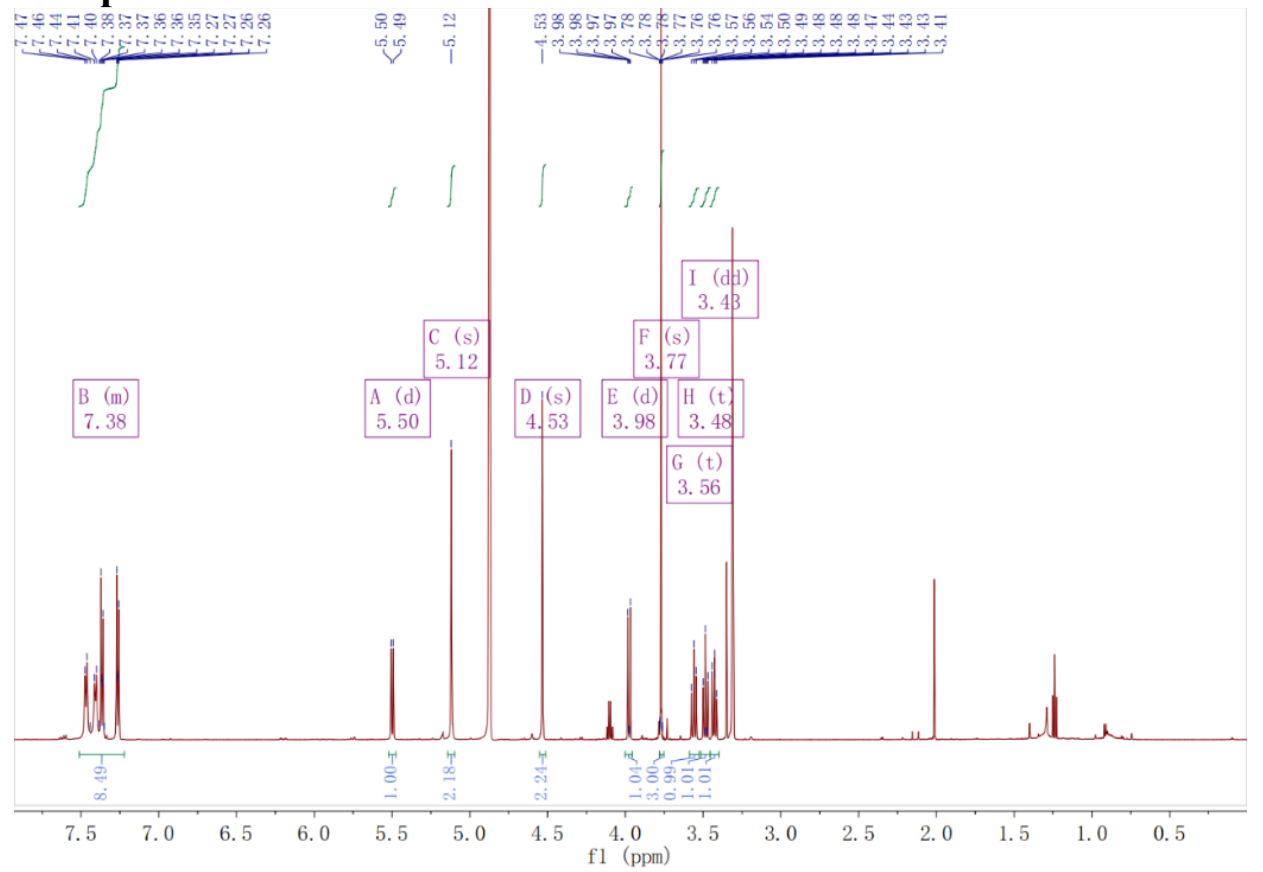

${ }^{1} \mathrm{H}$ NMR $\left(600 \mathrm{MHz}\right.$, Methanol- $\left.d_{4}\right) \delta 7.50-7.23(\mathrm{~m}, 8 \mathrm{H}, \mathrm{Ar}), 5.50(\mathrm{~d}, J=8.0 \mathrm{~Hz}, 1 \mathrm{H}$, Glu 1-H), 5.12 (s, 2H, Ar- $\mathrm{CH}_{2}$ ), 4.53 (s, 2H, Ar- $\mathrm{CH}_{2}$ ), 3.98 (d, $J=9.7 \mathrm{~Hz}, 1 \mathrm{H}$, Glu 5-H), 3.77 (s, 3H, $\left.\mathrm{COOCH}_{3}\right), 3.56$ (t, $J=9.3 \mathrm{~Hz}, 1 \mathrm{H}$, Glu 2-H), 3.48 (t, $J=9.0 \mathrm{~Hz}, 1 \mathrm{H}$, Glu 3-H), 3.43 (dd, $J=9.1 \mathrm{~Hz}, 1 \mathrm{H}$, Glu 4-H). 


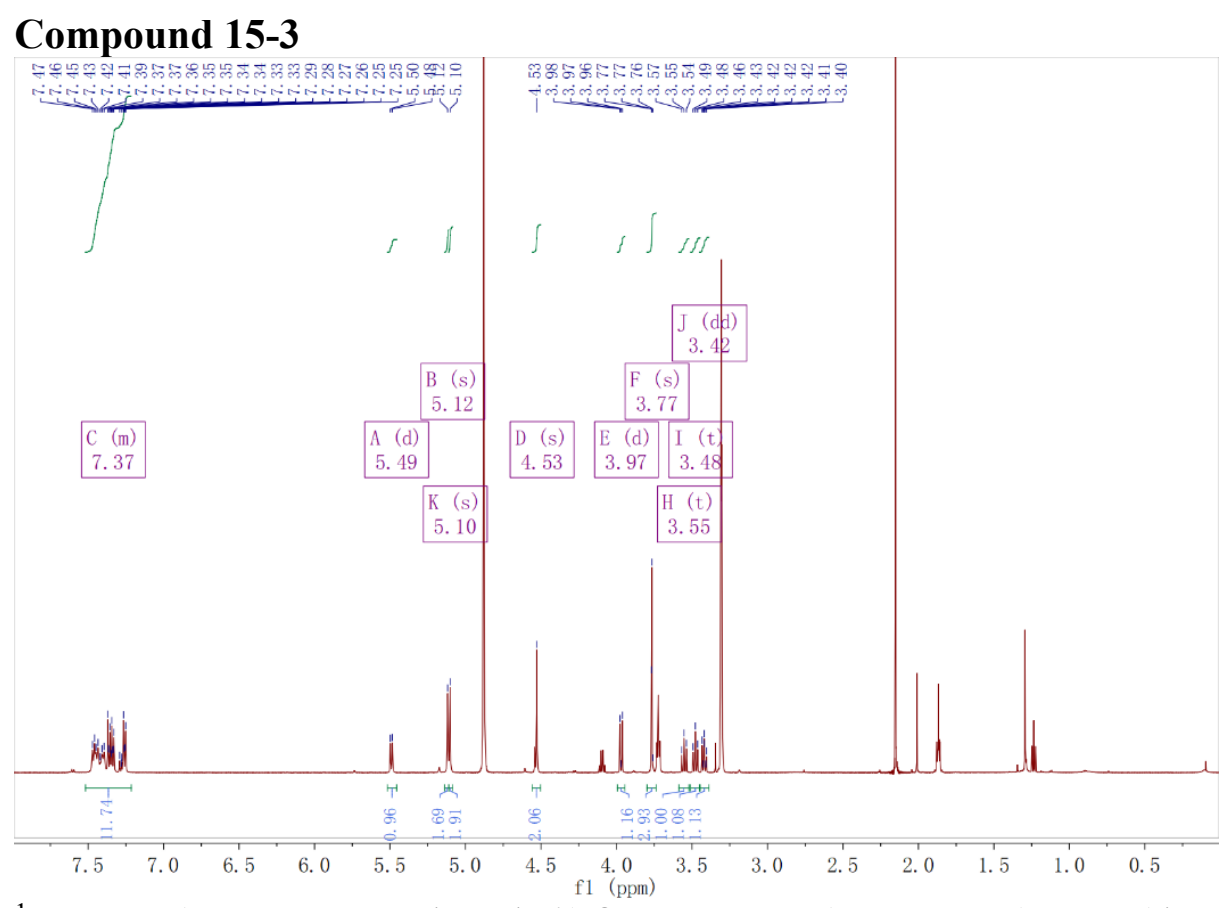

${ }^{1} \mathrm{H}$ NMR (600 MHz, Methanol- $d_{4}$ ) $\delta 7.52-7.21(\mathrm{~m}, 12 \mathrm{H}, \mathrm{Ar}), 5.49$ (d, $J=8.0 \mathrm{~Hz}, 1 \mathrm{H}$, Glu 1-H), 5.12 (s, $\left.2 \mathrm{H}, \mathrm{Ar}-\mathrm{CH}_{2}\right), 5.10$ (s, 2H, $\left.\mathrm{Ar}-\mathrm{CH}_{2}\right), 4.53$ (s, $\left.2 \mathrm{H}, \mathrm{Ar}-\mathrm{CH}_{2}\right), 3.97$ (d, $J=9.7$ $\mathrm{Hz}, 1 \mathrm{H}$, Glu $5-\mathrm{H}), 3.77\left(\mathrm{~s}, 3 \mathrm{H}, \mathrm{COOCH}_{3}\right), 3.55(\mathrm{t}, J=9.3 \mathrm{~Hz}, 1 \mathrm{H}$, Glu 2-H), $3.48(\mathrm{t}, J=$ $9.0 \mathrm{~Hz}, 1 \mathrm{H}$, Glu 3-H), 3.42 (dd, $J=9.1 \mathrm{~Hz}, 1 \mathrm{H}$, Glu 4-H).

\section{Compound 16-1,2,3}

$3.2 \mathrm{mmol}$ of $15-1,2,3$ were dissolved in a mixture of $25 \mathrm{~mL}$ dried propargyl alcohol and 6 $\mathrm{mL}$ dried THF, to which $14 \mathrm{mg}$ of sodium $(0.6 \mathrm{mmol})$ dissolved in $15 \mathrm{~mL}$ dried propargyl alcohol was added. After 40 minutes of reaction at room temperature, the mixture was neutralized with silica and purified by column chromatography ( $4 \%$ methanol/ethyl acetate) to get compound 16-1,2,3. Yield of 16-1,2,3: 58.8, 81.2, and 71.4\%. 


\section{Compound 16-2}

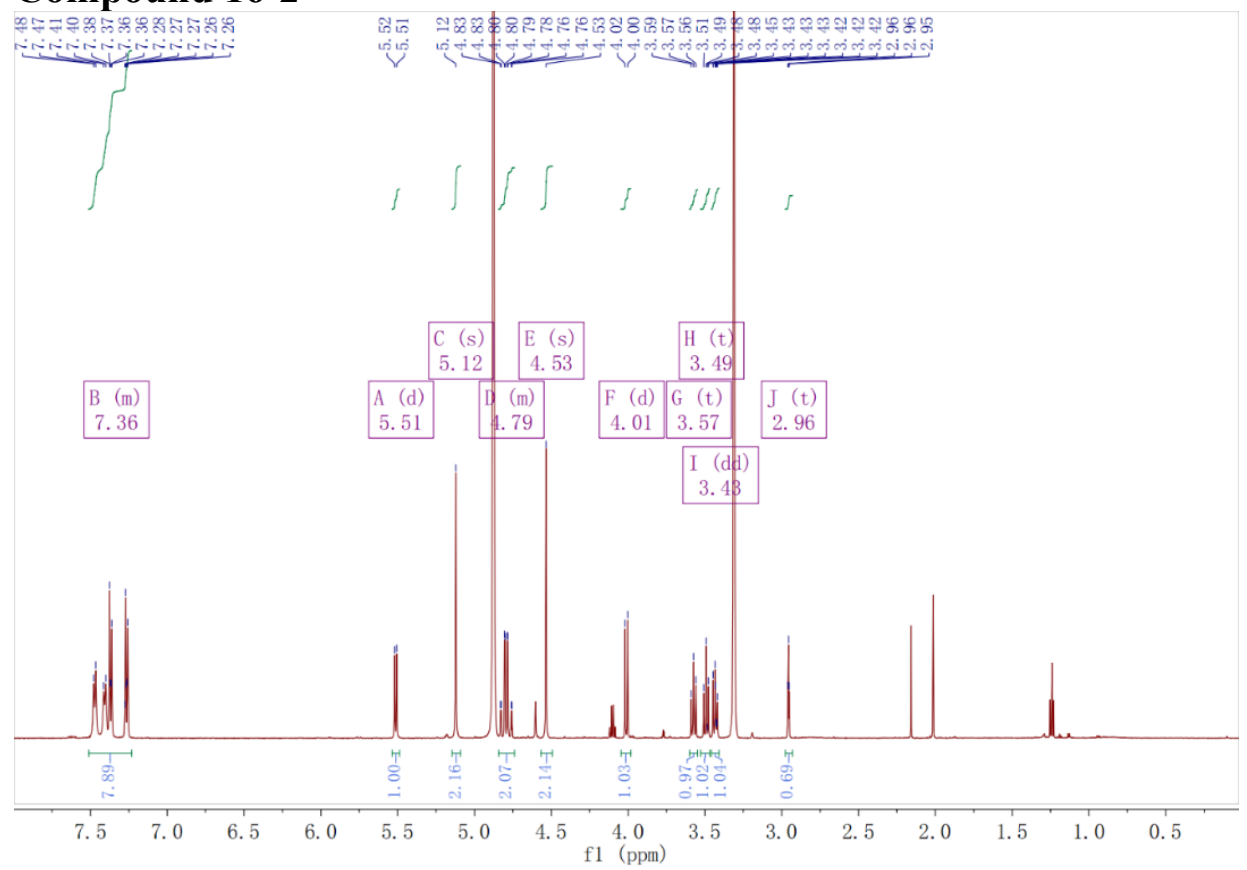

${ }^{1} \mathrm{H}$ NMR (600 MHz, Methanol- $\left.d_{4}\right) \delta 7.50-7.24(\mathrm{~m}, 8 \mathrm{H}, \mathrm{Ar}), 5.51(\mathrm{~d}, J=8.0 \mathrm{~Hz}, 1 \mathrm{H}$, Glu 1-H), 5.12 (s, 2H, Ar-CH $), 4.84-4.74$ (m, 2H, O-CH $2-\mathrm{C} \equiv \mathrm{CH}), 4.53$ (s, 2H, Ar-CH $-\mathrm{OH}$ ), $4.01(\mathrm{~d}, J=9.7 \mathrm{~Hz}, 1 \mathrm{H}$, Glu 5-H), 3.57 (t, $J=9.3 \mathrm{~Hz}, 1 \mathrm{H}$, Glu 2-H), 3.49 (t, $J=9.0 \mathrm{~Hz}$, 1H, Glu 3-H), 3.43 (dd, $J=9.1 \mathrm{~Hz}, 1 \mathrm{H}$, Glu 4-H), 2.96 (t, $J=2.5 \mathrm{~Hz}, 1 \mathrm{H},-\mathrm{C} \equiv \mathrm{CH})$.

\section{Compound 17-1,2,3}

To a solution of $1.88 \mathrm{mmol} 16-1,2,3 \mathrm{in} 60 \mathrm{ml}$ of acetonitrile and $8 \mathrm{ml}$ THF was added 194 $\mathrm{mg}(2.46 \mathrm{mmol})$ of pyridine and $454 \mathrm{mg}(2.26 \mathrm{mmol})$ 4-nitrophenyl chloroformate $(\mathrm{Cl}-$ $\mathrm{COOPh} \cdot \mathrm{NO}_{2}$ ). After stirring for 2 hours at $0{ }^{\circ} \mathrm{C}$, the reaction mixture was concentrated and the residue was purified by column chromatography ( $8 \%$ methanol/dichloromethane). Yield of 17-1,2,3: 48.9, 47.0 and 24.3\%. 


\section{Compound 17-1}

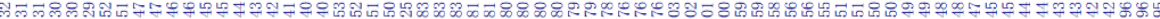

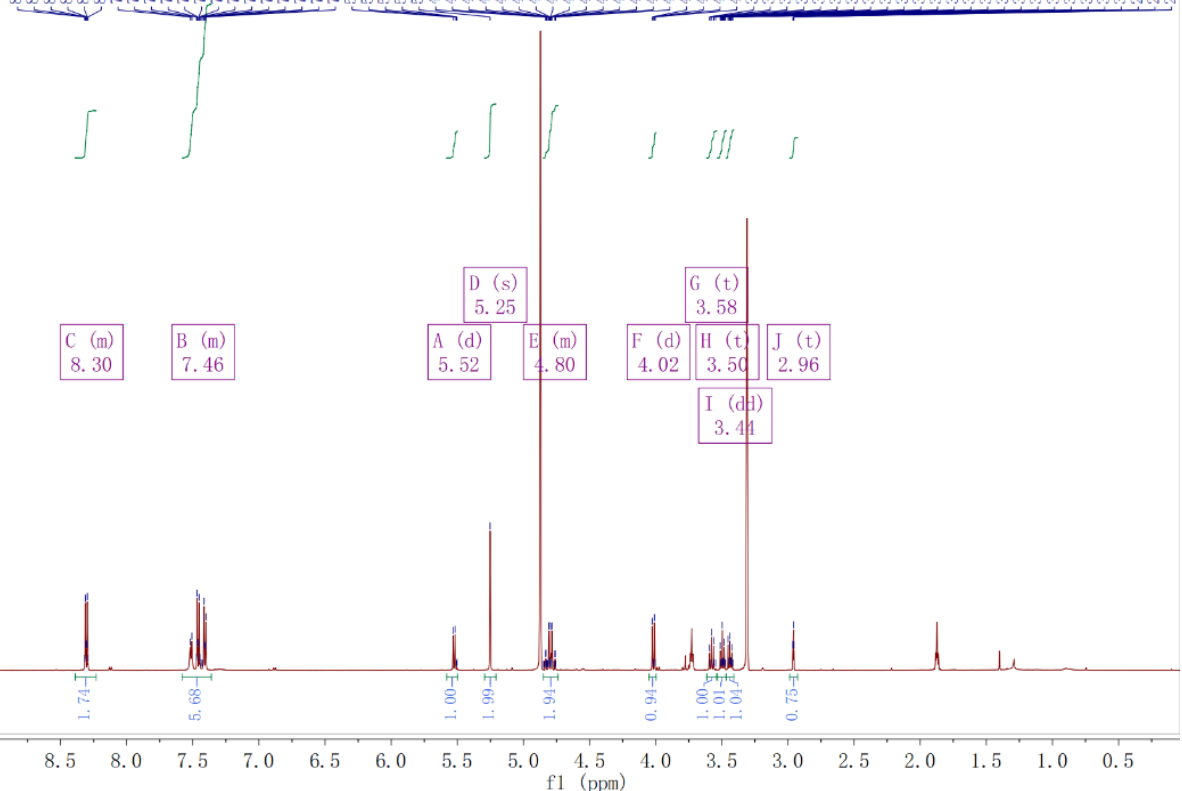

${ }^{1} \mathrm{H}$ NMR $\left(600 \mathrm{MHz}\right.$, Methanol- $\left.d_{4}\right) \delta 8.39-8.23\left(\mathrm{~m}, 2 \mathrm{H}, \mathrm{Ar}-\mathrm{NO}_{2}\right), 7.58-7.36$ (m, 6H, Ar), $5.52(\mathrm{~d}, J=8.1 \mathrm{~Hz}, 1 \mathrm{H}, \mathrm{Glu} 1-\mathrm{H}), 5.25\left(\mathrm{~s}, 2 \mathrm{H}, \mathrm{Ar}-\mathrm{CH}_{2}\right), 4.85-4.74\left(\mathrm{~m}, 2 \mathrm{H}, \mathrm{O}-\mathrm{CH}_{2}-\mathrm{C} \equiv \mathrm{CH}\right)$, $4.02(\mathrm{~d}, J=9.7 \mathrm{~Hz}, 1 \mathrm{H}$, Glu $5-\mathrm{H}), 3.58(\mathrm{t}, J=9.3 \mathrm{~Hz}, 1 \mathrm{H}, \mathrm{Glu} 2-\mathrm{H}), 3.50(\mathrm{t}, J=9.0 \mathrm{~Hz}$, 1H, Glu 3-H), 3.44 (dd, $J=9.1 \mathrm{~Hz}, 1 \mathrm{H}$, Glu 4-H), 2.96 (t, $J=2.5 \mathrm{~Hz}, 1 \mathrm{H},-\mathrm{C} \equiv \mathrm{CH})$.

\section{Compound 17-2}

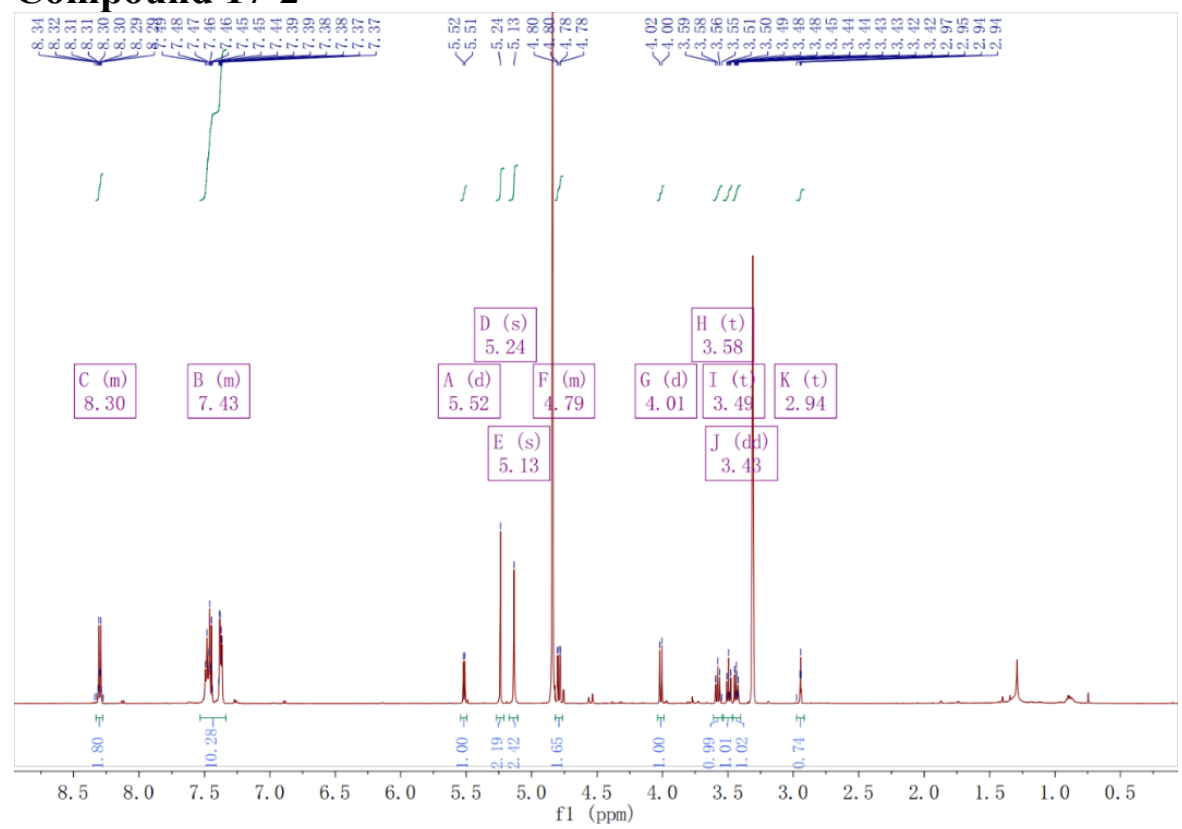

${ }^{1} \mathrm{H}$ NMR $\left(600 \mathrm{MHz}\right.$, Methanol- $\left.d_{4}\right) \delta 8.33-8.28\left(\mathrm{~m}, 2 \mathrm{H}, \mathrm{Ar}-\mathrm{NO}_{2}\right), 7.53-7.34(\mathrm{~m}, 10 \mathrm{H}$, Ar), $5.52\left(\mathrm{~d}, J=8.0 \mathrm{~Hz}, 1 \mathrm{H}\right.$, Glu 1-H), $5.24\left(\mathrm{~s}, 2 \mathrm{H}, \mathrm{Ar}-\mathrm{CH}_{2}\right), 5.13\left(\mathrm{~s}, 2 \mathrm{H}, \mathrm{Ar}-\mathrm{CH}_{2}\right), 4.82-$ $4.76\left(\mathrm{~m}, 2 \mathrm{H}, \mathrm{O}-\mathrm{CH}_{2}-\mathrm{C} \equiv \mathrm{CH}\right), 4.01(\mathrm{~d}, J=9.7 \mathrm{~Hz}, 1 \mathrm{H}$, Glu $5-\mathrm{H}), 3.58(\mathrm{t}, J=9.3 \mathrm{~Hz}, 1 \mathrm{H}$, Glu 2-H), 3.49 (t, $J=9.0 \mathrm{~Hz}, 1 \mathrm{H}$, Glu 3-H), 3.43 (dd, $J=9.1 \mathrm{~Hz}, 1 \mathrm{H}$, Glu 4-H), 2.94 (t, $J$ $=2.5 \mathrm{~Hz}, 1 \mathrm{H},-\mathrm{C} \equiv \mathrm{CH})$. 


\section{Compound 17-3}

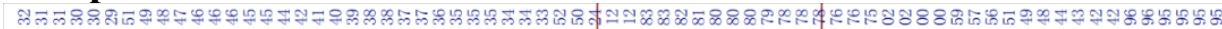

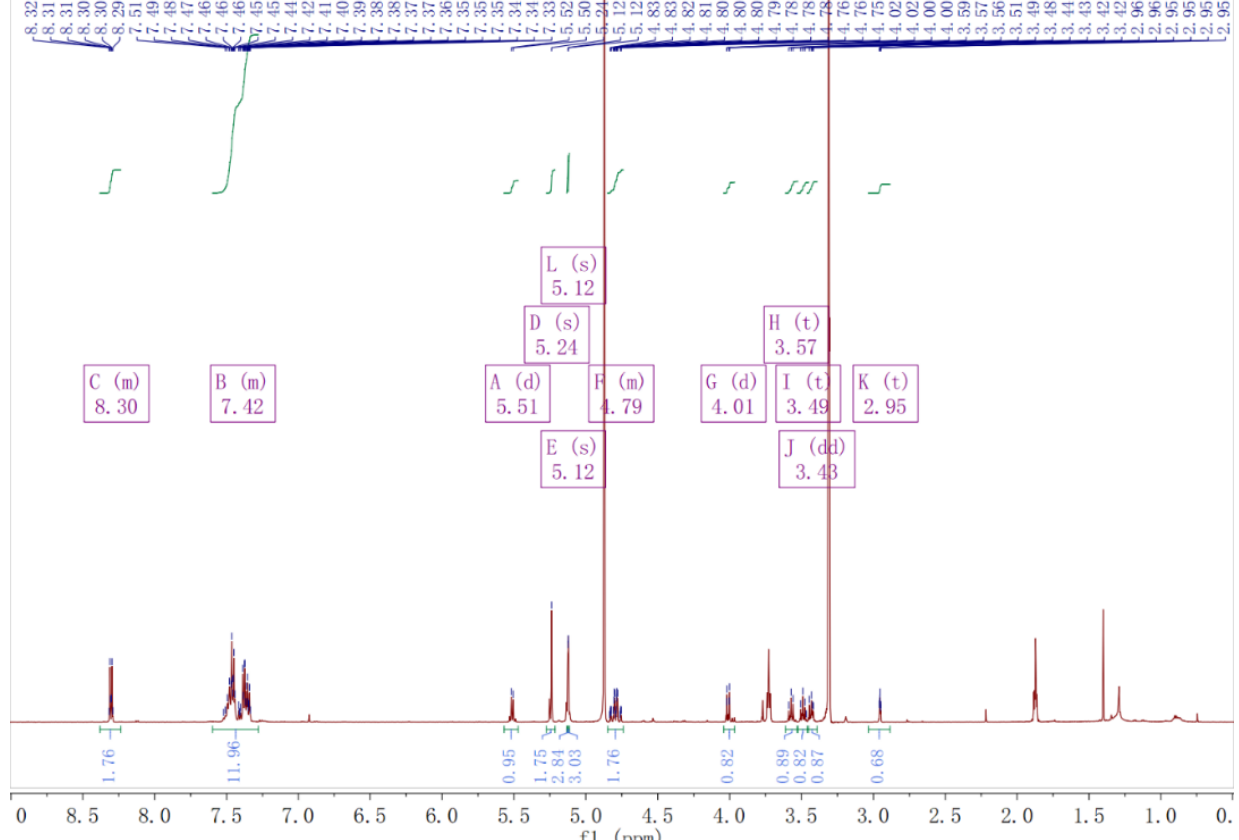

${ }^{1} \mathrm{H}$ NMR $\left(600 \mathrm{MHz}\right.$, Methanol- $\left.d_{4}\right) \delta 8.38-8.24\left(\mathrm{~m}, 2 \mathrm{H}, \mathrm{Ar}-\mathrm{NO}_{2}\right), 7.60-7.28(\mathrm{~m}, 14 \mathrm{H}$, Ar), $5.51\left(\mathrm{~d}, J=8.0 \mathrm{~Hz}, 1 \mathrm{H}\right.$, Glu 1-H), $5.24\left(\mathrm{~s}, 2 \mathrm{H}, \mathrm{Ar}-\mathrm{CH}_{2}\right), 5.12\left(\mathrm{~s}, 2 \mathrm{H}, \mathrm{Ar}-\mathrm{CH}_{2}\right), 5.11$ $\left(\mathrm{s}, 2 \mathrm{H}, \mathrm{Ar}-\mathrm{CH}_{2}\right), 4.85-4.74\left(\mathrm{~m}, 2 \mathrm{H}, \mathrm{O}-\mathrm{CH}_{2}-\mathrm{C} \equiv \mathrm{CH}\right), 4.01(\mathrm{~d}, J=9.7 \mathrm{~Hz}, 1 \mathrm{H}, \mathrm{Glu} 5-\mathrm{H})$, 3.57 (t, $J=9.3 \mathrm{~Hz}, 1 \mathrm{H}$, Glu 2-H), 3.49 (t, $J=9.0 \mathrm{~Hz}, 1 \mathrm{H}$, Glu 3-H), 3.43 (dd, $J=9.1 \mathrm{~Hz}$, 1H, Glu 4-H), 2.95 (t, $J=2.5 \mathrm{~Hz}, 1 \mathrm{H},-\mathrm{C} \equiv \mathrm{CH})$.

\section{Compound 18-1,2,3}

$0.49 \mathrm{mmol}$ of $17-1,2,3$ was dissolved in $14 \mathrm{~mL}$ DMF and $175 \mathrm{mg}(0.4 \mathrm{mmol})$ of IMDQ $2 \mathrm{HCl}$ and $113 \mu \mathrm{L}(0.8 \mathrm{mmol})$ of TEA were added to the solution. After overnight reaction at room temperature, the crude mixture was purified by column chromatography (20\% methanol/ethyl acetate) to get 18-1,2,3. Yield of 18-1,2,3: 96.7, 96.2 and $93.4 \%$. 


\section{Compound 18-1}

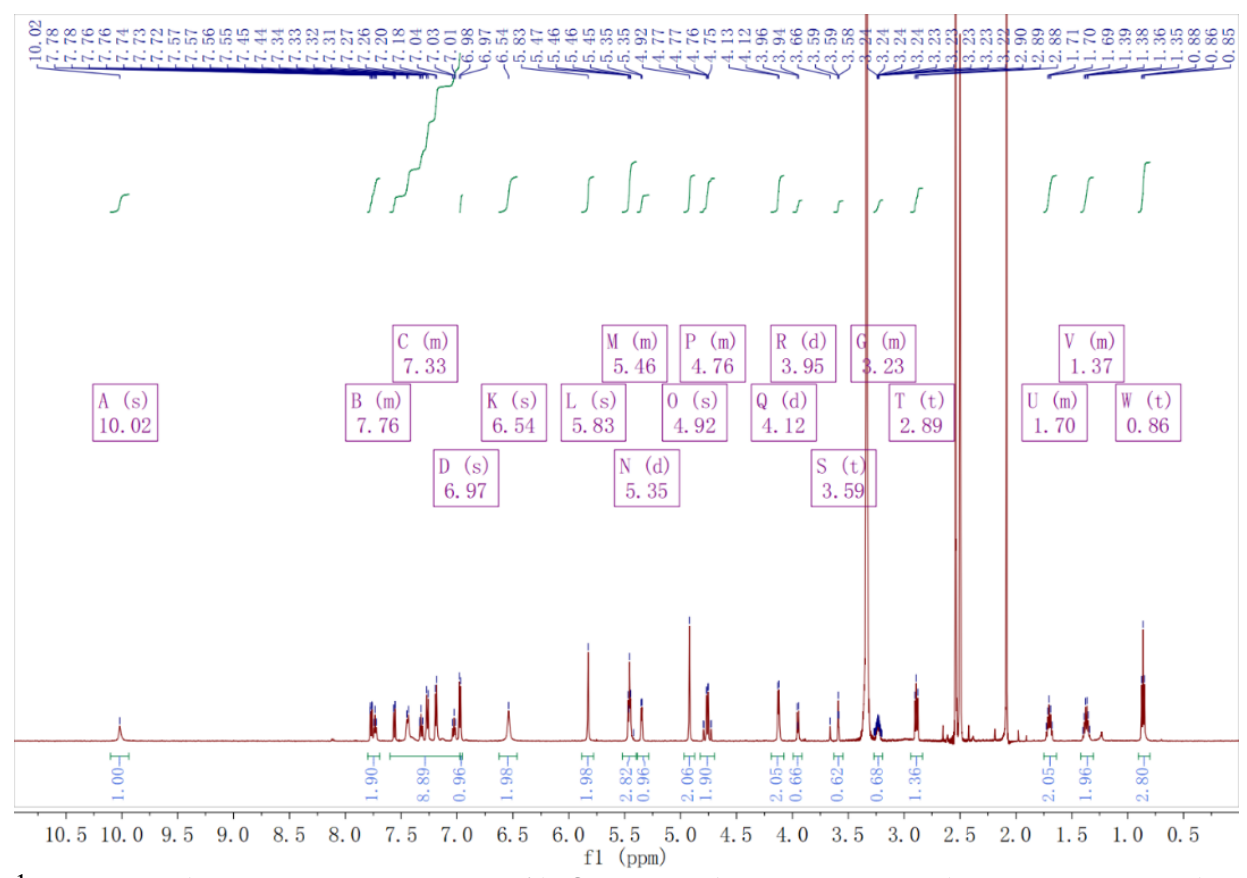

${ }^{1} \mathrm{H}$ NMR (600 MHz, DMSO- $\left.d_{6}\right) \delta 10.02$ (s, 1H, Ar-NH), 7.80 - 7.69 (m, 2H, Ar), $7.62-$ $6.98(\mathrm{~m}, 10 \mathrm{H}, \mathrm{Ar}), 6.97$ (s, 1H, COONH), 6.54 (s, 2H, $\left.-\mathrm{NH}_{2}\right), 5.83$ (s, 2H, $\left.\mathrm{Ar}-\mathrm{CH}_{2}\right), 5.52$ -5.40 (m, 3H, Glu 1-H, Glu-OH), 5.35 (d, $J=4.7 \mathrm{~Hz}, 1 \mathrm{H}, \mathrm{Glu}-\mathrm{OH}), 4.92$ (s, $2 \mathrm{H}, \mathrm{Ar}-\mathrm{CH}_{2}$ ), $4.82-4.70\left(\mathrm{~m}, 2 \mathrm{H}, \mathrm{O}-\mathrm{CH}_{2}-\mathrm{C} \equiv \mathrm{CH}\right), 4.12\left(\mathrm{~d}, J=6.1 \mathrm{~Hz}, 2 \mathrm{H}, \mathrm{Ar}_{-} \mathrm{CH}_{2}-\mathrm{NH}\right), 3.95(\mathrm{~d}, J=9.2$ $\mathrm{Hz}, 1 \mathrm{H}$, Glu 5-H), 3.59 (t, $J=2.5 \mathrm{~Hz}, 1 \mathrm{H},-\mathrm{C} \equiv \mathrm{CH}), 3.27-3.19$ (m, 3H, Glu 2,3,4-H), 2.89 $\left(\mathrm{t}, J=7.7 \mathrm{~Hz}, 2 \mathrm{H},-\mathrm{CH}_{2}\right), 1.75-1.64\left(\mathrm{~m}, 2 \mathrm{H},-\mathrm{CH}_{2}\right), 1.42-1.31\left(\mathrm{~m}, 2 \mathrm{H},-\mathrm{CH}_{2}\right), 0.86(\mathrm{t}, J$ $\left.=7.4 \mathrm{~Hz}, 3 \mathrm{H},-\mathrm{CH}_{3}\right)$.

$\mathrm{m} / \mathrm{z}[\mathrm{M}+\mathrm{H}]^{+}=767.3$ (theoretical), found $=767.3$. 


\section{Compound 18-2}

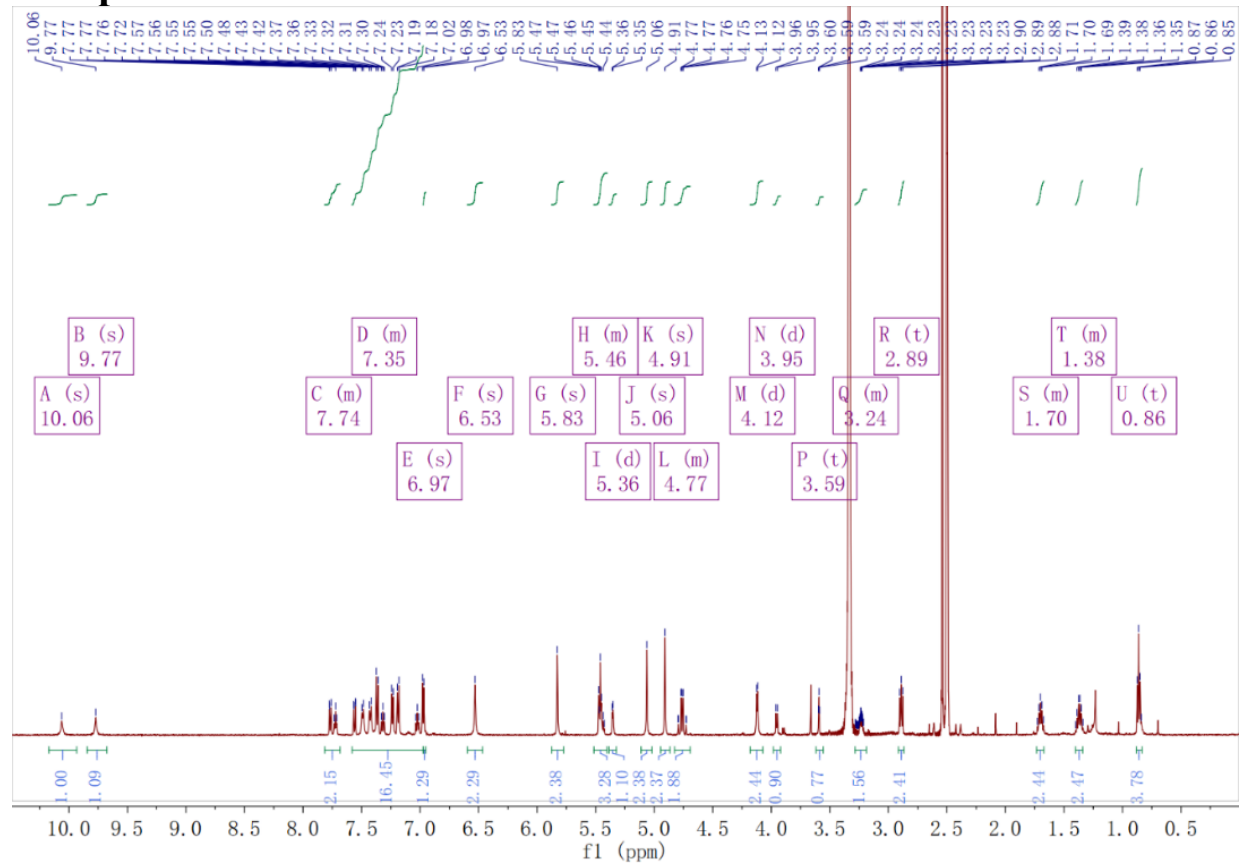

${ }^{1} \mathrm{H}$ NMR (600 MHz, DMSO-d $d_{6} \delta 10.06$ (s, 1H, Ar-NH), 9.77 (s, 1H, Ar-NH), $7.81-7.68$ (m, 2H, Ar), $7.60-6.98(\mathrm{~m}, 14 \mathrm{H}, \mathrm{Ar}), 6.97(\mathrm{~s}, 1 \mathrm{H}, \mathrm{COONH}), 6.53\left(\mathrm{~s}, 2 \mathrm{H},-\mathrm{NH}_{2}\right), 5.83(\mathrm{~s}$, $\left.2 \mathrm{H}, \mathrm{Ar}-\mathrm{CH}_{2}\right), 5.51-5.40$ (m, 3H, Glu 1-H, Glu-OH), 5.36 (d, $\left.J=4.5 \mathrm{~Hz}, 1 \mathrm{H}, \mathrm{Glu}-\mathrm{OH}\right)$, $5.06\left(\mathrm{~s}, 2 \mathrm{H}, \mathrm{Ar}-\mathrm{CH}_{2}\right), 4.91\left(\mathrm{~s}, 2 \mathrm{H}, \mathrm{Ar}-\mathrm{CH}_{2}\right), 4.83-4.69\left(\mathrm{~m}, 2 \mathrm{H}, \mathrm{O}_{-}-\mathrm{CH}_{2}-\mathrm{C} \equiv \mathrm{CH}\right), 4.12(\mathrm{~d}, J$ $\left.=6.1 \mathrm{~Hz}, 2 \mathrm{H}, \mathrm{Ar}_{-} \mathrm{CH}_{2}-\mathrm{NH}\right), 3.95(\mathrm{~d}, J=9.3 \mathrm{~Hz}, 1 \mathrm{H}$, Glu $5-\mathrm{H}), 3.59(\mathrm{t}, J=2.4 \mathrm{~Hz}, 1 \mathrm{H},-$ $\mathrm{C} \equiv \mathrm{CH}), 3.28-3.19\left(\mathrm{~m}, 3 \mathrm{H}\right.$, Glu 2,3,4-H), 2.89 (t, $\left.J=7.7 \mathrm{~Hz}, 2 \mathrm{H},-\mathrm{CH}_{2}\right), 1.73-1.67(\mathrm{~m}$, $\left.2 \mathrm{H},-\mathrm{CH}_{2}\right), 1.40-1.34\left(\mathrm{~m}, 2 \mathrm{H},-\mathrm{CH}_{2}\right), 0.86\left(\mathrm{t}, J=7.3 \mathrm{~Hz}, 3 \mathrm{H},-\mathrm{CH}_{3}\right)$.

$\mathrm{m} / \mathrm{z}[\mathrm{M}+\mathrm{H}]^{+}=916.3$ (theoretical), found $=916.3$. 


\section{Compound 18-3}

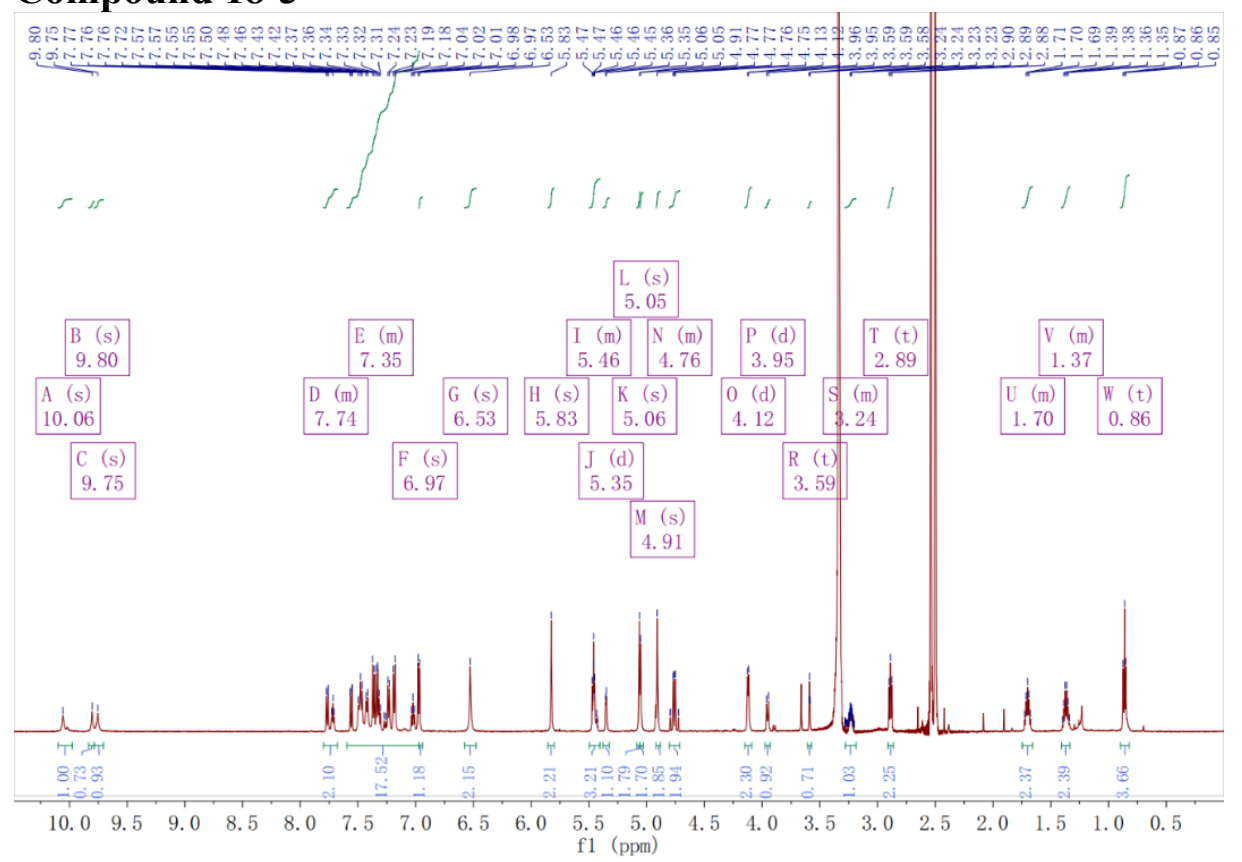

${ }^{1} \mathrm{H}$ NMR (600 MHz, DMSO- $d_{6}$ ) $\delta 10.06$ (s, $\left.1 \mathrm{H}, \mathrm{Ar}-\mathrm{NH}\right), 9.80$ (s, 1H, Ar-NH), 9.75 (s, $1 \mathrm{H}$, Ar-NH), $7.80-7.68$ (m, 2H, Ar), $7.58-6.98$ (m, 18H, Ar), 6.97 (s, 1H, COONH), 6.53 (s, $\left.2 \mathrm{H},-\mathrm{NH}_{2}\right), 5.83\left(\mathrm{~s}, 2 \mathrm{H}, \mathrm{Ar}-\mathrm{CH}_{2}\right), 5.50-5.41(\mathrm{~m}, 3 \mathrm{H}$, Glu 1-H, Glu-OH), 5.35 (d, $J=4.5$ $\mathrm{Hz}, 1 \mathrm{H}, \mathrm{Glu}-\mathrm{OH}), 5.06$ (s, 2H, Ar- $\mathrm{CH}_{2}$ ), 5.05 (s, 2H, Ar-CH $), 4.91$ (s, $\left.2 \mathrm{H}, \mathrm{Ar}_{-} \mathrm{CH}_{2}\right), 4.81$ $-4.71\left(\mathrm{~m}, 2 \mathrm{H}, \mathrm{O}-\mathrm{CH}_{2}-\mathrm{C} \equiv \mathrm{CH}\right), 4.12\left(\mathrm{~d}, J=6.2 \mathrm{~Hz}, 2 \mathrm{H}, \mathrm{Ar}-\mathrm{CH}_{2}-\mathrm{NH}\right), 3.95(\mathrm{~d}, J=9.0 \mathrm{~Hz}$, 1H, Glu 5-H), 3.59 (t, $J=2.4 \mathrm{~Hz}, 1 \mathrm{H},-\mathrm{C} \equiv \mathrm{CH}), 3.28-3.19(\mathrm{~m}, 3 \mathrm{H}, \mathrm{Glu} 2,3,4-\mathrm{H}), 2.89$ (t, $\left.J=7.7 \mathrm{~Hz}, 2 \mathrm{H},-\mathrm{CH}_{2}\right), 1.75-1.66\left(\mathrm{~m}, 2 \mathrm{H},-\mathrm{CH}_{2}\right), 1.41-1.34\left(\mathrm{~m}, 2 \mathrm{H},-\mathrm{CH}_{2}\right), 0.86(\mathrm{t}, J=$ $\left.7.4 \mathrm{~Hz}, 3 \mathrm{H},-\mathrm{CH}_{3}\right)$.

$\mathrm{m} / \mathrm{z}[\mathrm{M}+\mathrm{H}]^{+}=1065.4$ (theoretical), found $=1065.3$.

\section{PEG-GIn-IMDQ}

$1 \mathrm{mmol}$ of azide-functionalized PEG5/2/0.75k and $1.2 \mathrm{mmol}$ of $18-1,2,3$ were dissolved in $200 \mu \mathrm{L}$ of dried DMSO, to which $0.5 \mathrm{mg}(0.25 \mathrm{mmol})$ of $\mathrm{CuI}$ and $1 \mathrm{mg}(0.5 \mathrm{mmol})$ of sodium ascorbate were added. The reaction was kept at $40{ }^{\circ} \mathrm{C}$ for 24 hours. The reaction with PEG5k was processed by dialysis in DMSO and those with PEG2/0.75k were processed by column chromatography ( $30 \%$ methanol/ethyl acetate to THF). 


\section{PEG5k-GL1-IMDQ}

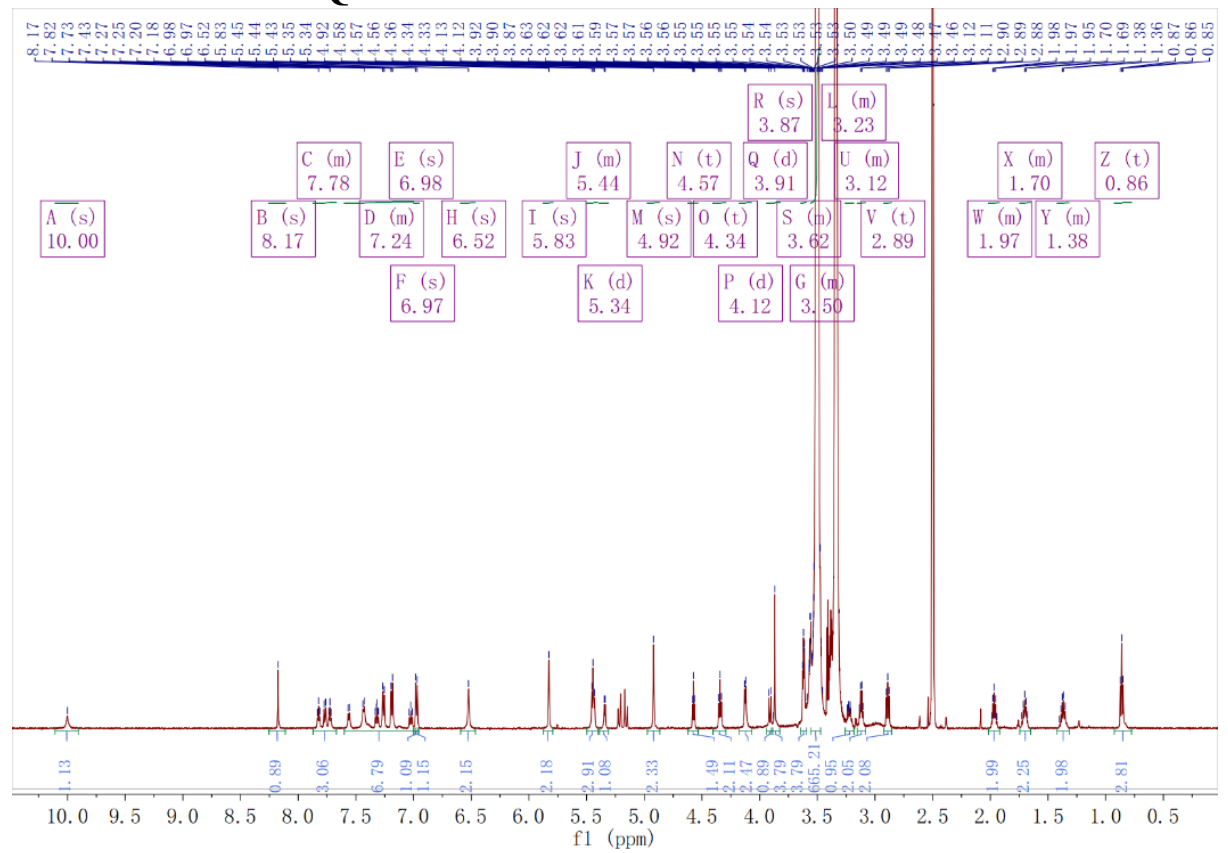

${ }^{1} \mathrm{H}$ NMR (600 MHz, DMSO- $d_{6}$ ) $\delta 10.00$ (s, $\left.1 \mathrm{H}, \mathrm{Ar}-\mathrm{NH}\right), 8.17$ (s, $1 \mathrm{H}$, triazyl), $7.87-7.67$ (m, 2H, Ar), $7.56-7.01$ (m, 10H, Ar), 6.98 (s, 1H, OCONH), 6.97 (s, 1H, COONH,) 6.52 $\left(\mathrm{s}, 2 \mathrm{H},-\mathrm{NH}_{2}\right), 5.83\left(\mathrm{~s}, 2 \mathrm{H}, \mathrm{Ar}-\mathrm{CH}_{2}-\mathrm{N}\right), 5.5-5.40(\mathrm{~m}, 3 \mathrm{H}, \mathrm{Glu} 1-\mathrm{H}$, Glu-OH), $5.34(\mathrm{~d}, J=$ $5.2 \mathrm{~Hz}, 1 \mathrm{H}, \mathrm{Glu}-\mathrm{OH}), 4.92\left(\mathrm{~s}, 2 \mathrm{H}, \mathrm{Ar}-\mathrm{CH}_{2}\right), 4.57\left(\mathrm{t}, J=5.5 \mathrm{~Hz}, 1 \mathrm{H},\left(\mathrm{O}-\mathrm{CH}_{2}-\mathrm{CH}_{2}-\right)_{112}-\mathrm{OH}\right)$, $4.34\left(\mathrm{t}, J=7.1 \mathrm{~Hz}, 2 \mathrm{H}, \mathrm{COOCH}_{2}\right), 4.12\left(\mathrm{~d}, J=6.2 \mathrm{~Hz}, 2 \mathrm{H}, \mathrm{Ar}_{-} \mathrm{CH}_{2}-\mathrm{NH}\right), 3.91(\mathrm{~d}, J=9.3$ $\mathrm{Hz}, 1 \mathrm{H}$, Glu 5-H), 3.87 (s, 2H, - $\mathrm{CH}_{2}$-triazyl), $3.64-3.60\left(\mathrm{~m}, 2 \mathrm{H}, \mathrm{OCH}_{2} \mathrm{O}\right), 3.59-3.45(\mathrm{~m}$, $\left.448 \mathrm{H},\left(\mathrm{O}-\mathrm{CH}_{2}-\mathrm{CH}_{2}-\right)_{112}\right), 3.26-3.18\left(\mathrm{~m}, 3 \mathrm{H}\right.$, Glu 2,3,4-H), $3.15-3.08\left(\mathrm{~m}, 2 \mathrm{H},-\mathrm{CH}_{2}\right)$, $2.89\left(\mathrm{t}, J=7.7 \mathrm{~Hz}, 2 \mathrm{H},-\mathrm{CH}_{2}\right), 2.02-1.92\left(\mathrm{~m}, 2 \mathrm{H},-\mathrm{CH}_{2}-\mathrm{CH}_{2}\right.$-triazyl), $1.74-1.65(\mathrm{~m}, 2 \mathrm{H}$, $\left.-\mathrm{CH}_{2}\right), 1.42-1.32\left(\mathrm{~m}, 2 \mathrm{H},-\mathrm{CH}_{2}\right), 0.86\left(\mathrm{t}, J=7.3 \mathrm{~Hz}, 3 \mathrm{H},-\mathrm{CH}_{3}\right)$. Yield: $97.3 \%$. 


\section{PEG5k-GL2-IMDQ}

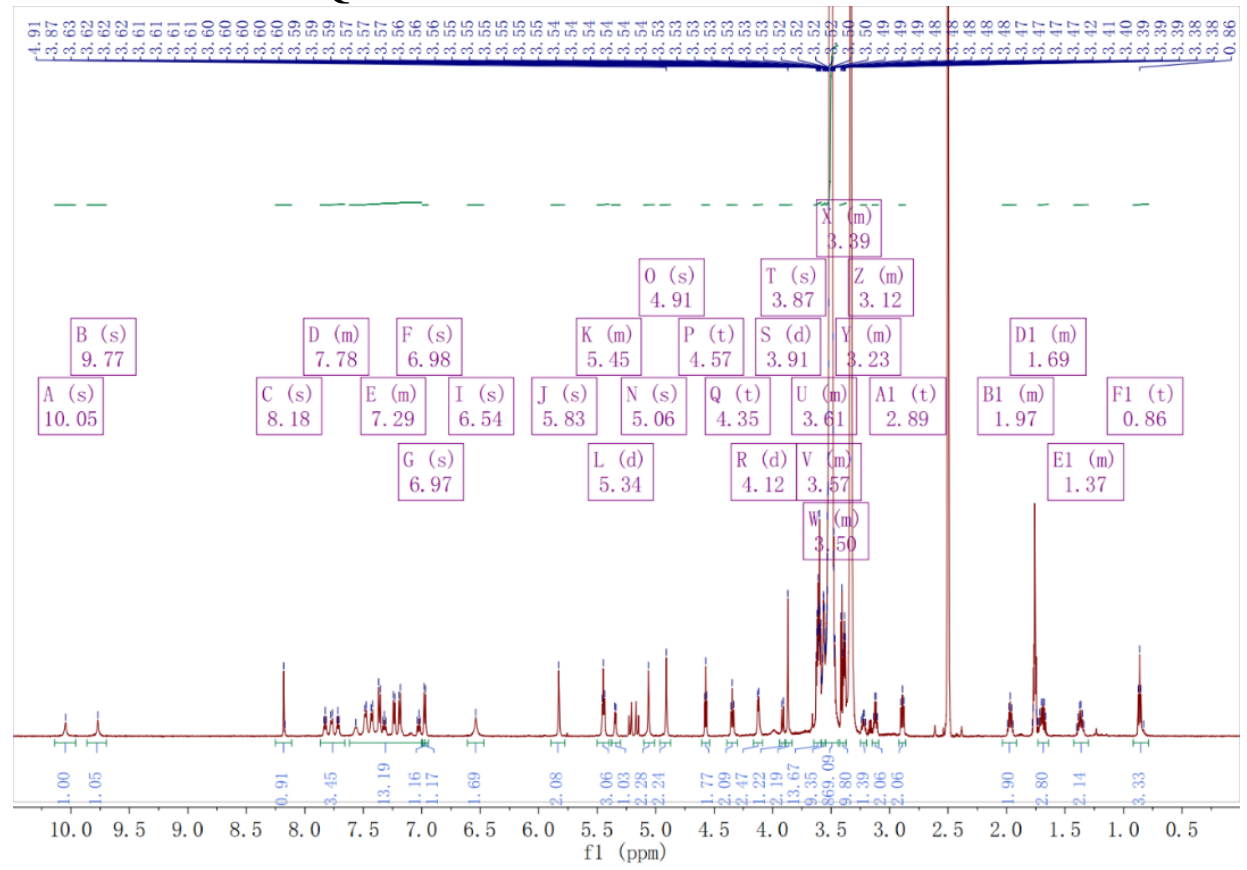

${ }^{1} \mathrm{H}$ NMR (600 MHz, DMSO-d $) \delta 10.05$ (s, 1H, Ar-NH), 9.77 (s, 1H, Ar-NH), 8.18 (s, 1H, triazyl), $7.87-7.66(\mathrm{~m}, 2 \mathrm{H}, \mathrm{Ar}), 7.62-7.00(\mathrm{~m}, 14 \mathrm{H}, \mathrm{Ar}), 6.98(\mathrm{~s}, 1 \mathrm{H}, \mathrm{OCONH}), 6.97$ (s, $1 \mathrm{H}, \mathrm{COONH}), 6.54\left(\mathrm{~s}, 2 \mathrm{H},-\mathrm{NH}_{2}\right), 5.83\left(\mathrm{~s}, 2 \mathrm{H}, \mathrm{Ar}_{-} \mathrm{CH}_{2}-\mathrm{N}\right), 5.50-5.40$ (m, 3H, Glu 1-H, Glu-OH), 5.34 (d, $J=5.2 \mathrm{~Hz}, 1 \mathrm{H}$, Glu-OH), 5.06 (s, 2H, Ar- $\left.\mathrm{CH}_{2}\right), 4.91\left(\mathrm{~s}, 2 \mathrm{H}, \mathrm{Ar}-\mathrm{CH}_{2}\right)$, $4.57\left(\mathrm{t}, J=5.5 \mathrm{~Hz}, 1 \mathrm{H},\left(\mathrm{O}-\mathrm{CH}_{2}-\mathrm{CH}_{2}-\right)_{112}-\mathrm{OH}\right), 4.35\left(\mathrm{t}, J=7.1 \mathrm{~Hz}, 2 \mathrm{H}, \mathrm{COOCH}_{2}\right), 4.12(\mathrm{~d}$, $\left.J=6.2 \mathrm{~Hz}, 2 \mathrm{H}, \mathrm{Ar}-\mathrm{CH}_{2}-\mathrm{NH}\right), 3.91$ (d, $J=9.3 \mathrm{~Hz}, 1 \mathrm{H}$, Glu 5-H), 3.87 (s, 2H, $-\mathrm{CH}_{2}$-triazyl), $3.65-3.59\left(\mathrm{~m}, 2 \mathrm{H}, \mathrm{OCH}_{2} \mathrm{O}\right), 3.55-3.44\left(\mathrm{~m}, 448 \mathrm{H},\left(\mathrm{O}-\mathrm{CH}_{2}-\mathrm{CH}_{2}\right)_{112}\right), 3.25-3.20(\mathrm{~m}, 3 \mathrm{H}$, Glu 2,3,4-H), $3.15-3.09$ (m, 2H, - $\left.\mathrm{CH}_{2}\right), 2.89$ (t, $\left.J=7.8 \mathrm{~Hz}, 2 \mathrm{H},-\mathrm{CH}_{2}\right), 2.04-1.92(\mathrm{~m}$, $2 \mathrm{H},-\mathrm{CH}_{2}-\mathrm{CH}_{2}$-triazyl), $1.73-1.64\left(\mathrm{~m}, 2 \mathrm{H},-\mathrm{CH}_{2}\right), 1.42-1.30\left(\mathrm{~m}, 2 \mathrm{H},-\mathrm{CH}_{2}\right), 0.86(\mathrm{t}, J=$ $\left.7.4 \mathrm{~Hz}, 3 \mathrm{H},-\mathrm{CH}_{3}\right)$. Yield: $86.7 \%$.

\section{HPLC chromatograms}

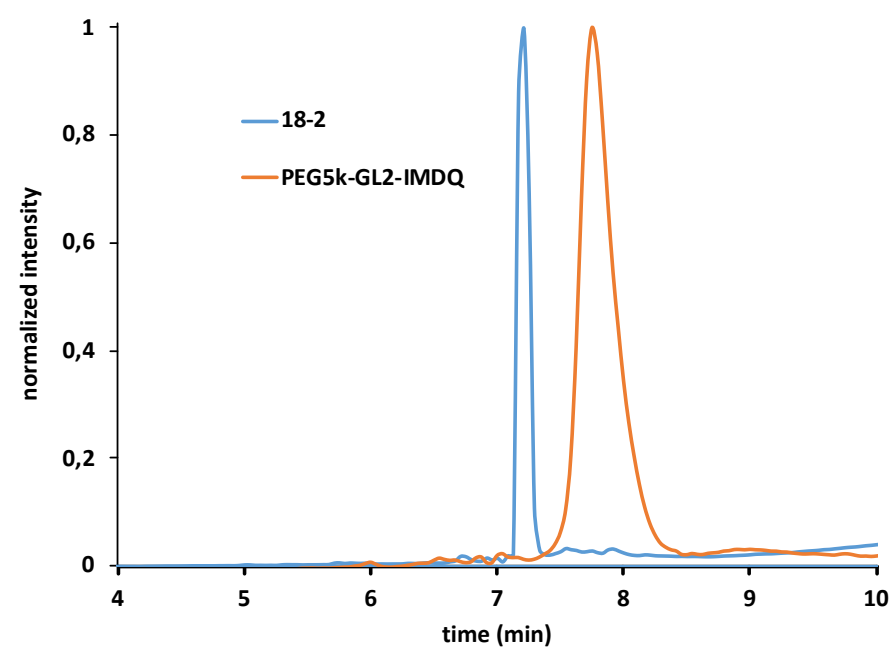




\section{PEG5k-GL3-IMDQ}

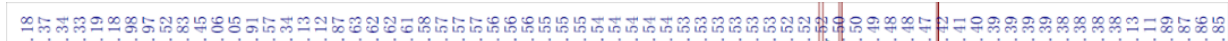

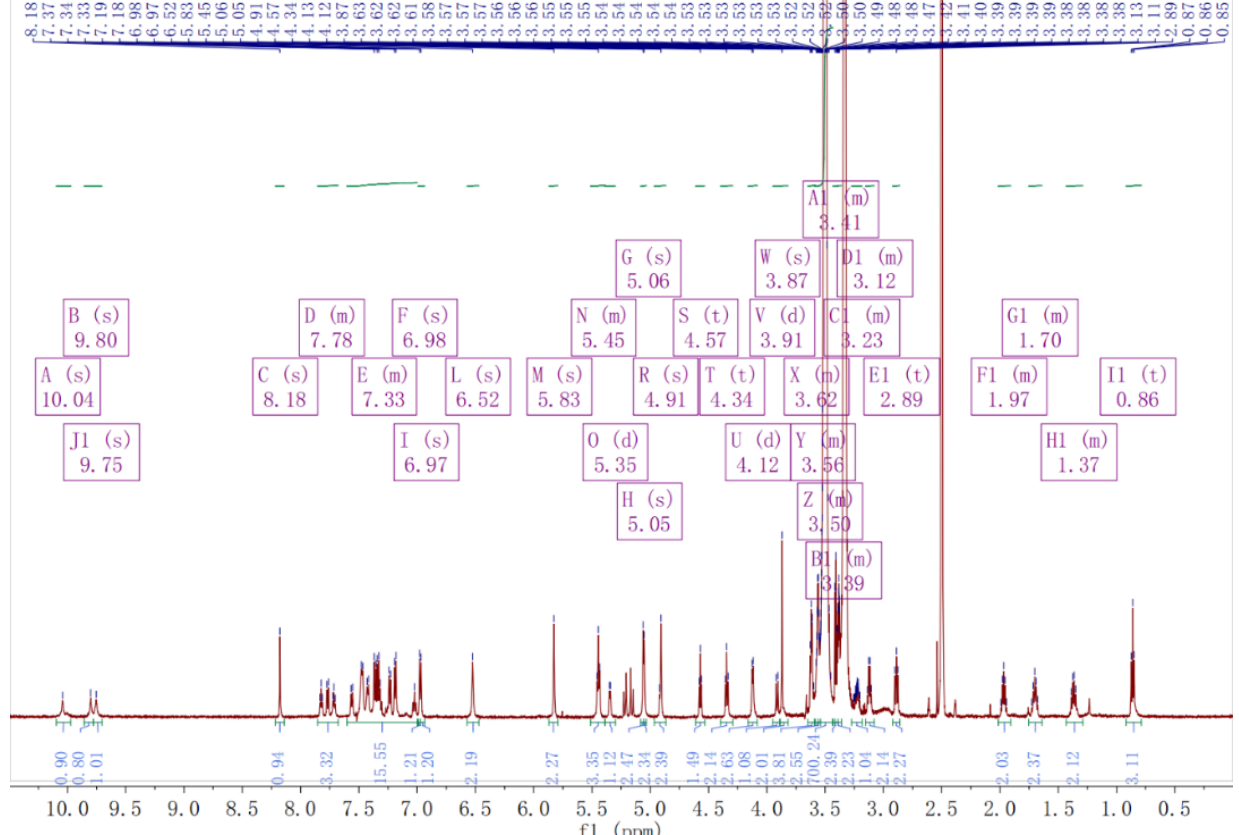

${ }^{1} \mathrm{H}$ NMR (600 MHz, DMSO-d $) \delta 10.04$ (s, 1H, Ar-NH), 9.80 (s, 1H, Ar-NH), 9.75 (s, 1H, Ar-NH), 8.18 (s, 1H, triazyl), $7.85-7.68(\mathrm{~m}, 2 \mathrm{H}, \mathrm{Ar}), 7.60-7.00(\mathrm{~m}, 18 \mathrm{H}, \mathrm{Ar}), 6.98(\mathrm{~s}$, $1 \mathrm{H}, \mathrm{OCONH}), 6.97(\mathrm{~s}, 1 \mathrm{H}, \mathrm{COONH}), 6.52\left(\mathrm{~s}, 2 \mathrm{H},-\mathrm{NH}_{2}\right), 5.83\left(\mathrm{~s}, 2 \mathrm{H}, \mathrm{Ar}_{-} \mathrm{CH}_{2}-\mathrm{N}\right), 5.50-$ $5.40\left(\mathrm{~m}, 3 \mathrm{H}\right.$, Glu 1-H, Glu-OH), 5.35 (d, $J=5.1 \mathrm{~Hz}, 1 \mathrm{H}$, Glu-OH), $5.06\left(\mathrm{~s}, 2 \mathrm{H}, \mathrm{Ar}-\mathrm{CH}_{2}\right)$, $5.05\left(\mathrm{~s}, 2 \mathrm{H}, \mathrm{Ar}-\mathrm{CH}_{2}\right), 4.91\left(\mathrm{~s}, 2 \mathrm{H}, \mathrm{Ar}-\mathrm{CH}_{2}\right), 4.57\left(\mathrm{t}, J=5.5 \mathrm{~Hz}, 1 \mathrm{H},\left(\mathrm{O}-\mathrm{CH}_{2}-\mathrm{CH}_{2}-\right)_{112}-\mathrm{OH}\right)$, $4.34\left(\mathrm{t}, J=7.1 \mathrm{~Hz}, 2 \mathrm{H}, \mathrm{COOCH}_{2}\right), 4.12\left(\mathrm{~d}, J=6.2 \mathrm{~Hz}, 2 \mathrm{H}, \mathrm{Ar}-\mathrm{CH}_{2}-\mathrm{NH}\right), 3.91(\mathrm{~d}, J=9.4$ $\mathrm{Hz}, 1 \mathrm{H}$, Glu 5-H), 3.87 (s, 2H, - $\mathrm{CH}_{2}$-triazyl), $3.65-3.58\left(\mathrm{~m}, 2 \mathrm{H}, \mathrm{OCH}_{2} \mathrm{O}\right), 3.56-3.44$ (m, $\left.448 \mathrm{H},\left(\mathrm{O}-\mathrm{CH}_{2}-\mathrm{CH}_{2}-\right)_{112}\right), 3.27-3.18\left(\mathrm{~m}, 3 \mathrm{H}\right.$, Glu 2,3,4-H), $3.15-3.08\left(\mathrm{~m}, 2 \mathrm{H},-\mathrm{CH}_{2}\right)$, $2.89\left(\mathrm{t}, J=7.8 \mathrm{~Hz}, 2 \mathrm{H},-\mathrm{CH}_{2}\right), 2.01-1.91\left(\mathrm{~m}, 2 \mathrm{H},-\mathrm{CH}_{2}-\mathrm{CH}_{2}\right.$-triazyl), $1.75-1.64(\mathrm{~m}, 2 \mathrm{H}$, $\left.-\mathrm{CH}_{2}\right), 1.43-1.29\left(\mathrm{~m}, 2 \mathrm{H},-\mathrm{CH}_{2}\right), 0.86\left(\mathrm{t}, J=7.4 \mathrm{~Hz}, 3 \mathrm{H},-\mathrm{CH}_{3}\right)$. Yield: $83.3 \%$. 


\section{PEG2k-GL2-IMDQ}

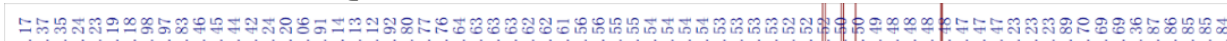

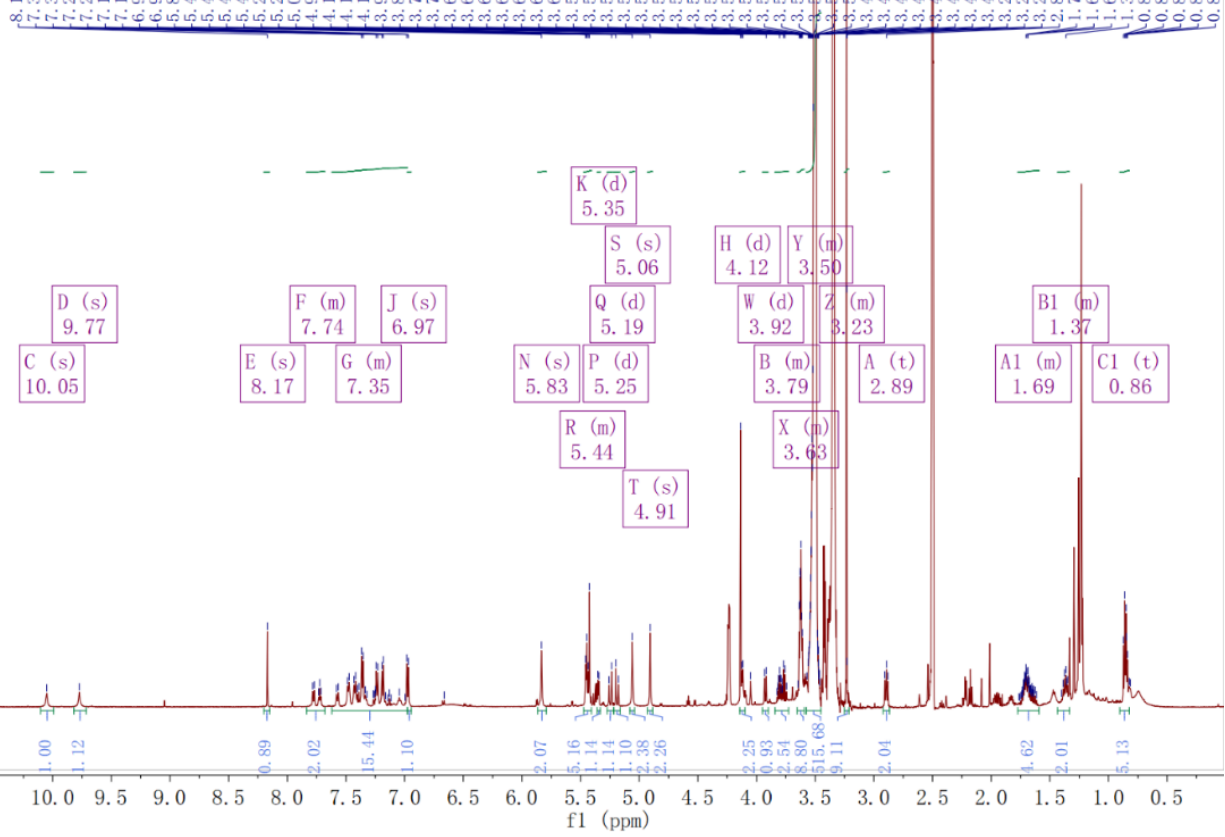

${ }^{1} \mathrm{H}$ NMR (600 MHz, DMSO-d $) \delta 10.05$ (s, 1H, Ar-NH), 9.77 (s, 1H, Ar-NH), 8.17 (s, 1H, triazyl), $7.84-7.68(\mathrm{~m}, 2 \mathrm{H}, \mathrm{Ar}), 7.62-6.98(\mathrm{~m}, 14 \mathrm{H}, \mathrm{Ar}), 6.97(\mathrm{~s}, 1 \mathrm{H}, \mathrm{COONH}), 6.63(\mathrm{~s}$, $\left.2 \mathrm{H},-\mathrm{NH}_{2}\right), 5.83$ (s, 2H, Ar- $\left.\mathrm{CH}_{2}-\mathrm{N}\right), 5.47-5.41$ (m, 3H, Glu-OH, Glu 1-H), 5.35 (d, $J=$ $5.1 \mathrm{~Hz}, 1 \mathrm{H}, \mathrm{Glu}-\mathrm{OH}), 5.06\left(\mathrm{~s}, 2 \mathrm{H}, \mathrm{Ar}-\mathrm{CH}_{2}\right), 4.91\left(\mathrm{~s}, 2 \mathrm{H}, \mathrm{Ar}-\mathrm{CH}_{2}\right), 4.12(\mathrm{~d}, J=6.2 \mathrm{~Hz}, 2 \mathrm{H}$, Ar- $\left.\mathrm{CH}_{2}-\mathrm{NH}\right), 3.92$ (d, $J=9.3 \mathrm{~Hz}, 1 \mathrm{H}$, Glu 5-H), $3.84-3.73\left(\mathrm{~m}, 2 \mathrm{H},-\mathrm{CH}_{2}\right.$-triazyl), $3.58-$ 3.45 (m, 180H, (O-CH2 $\left.\left.-\mathrm{CH}_{2}-\right)_{45}\right), 3.25-3.21\left(\mathrm{~m}, 6 \mathrm{H}\right.$, Glu 2,3,4-H, $\left.-\mathrm{CH}_{3}\right), 2.89$ (t, $J=7.8$ $\left.\mathrm{Hz}, 2 \mathrm{H},-\mathrm{CH}_{2}\right), 1.77-1.59\left(\mathrm{~m}, 2 \mathrm{H},-\mathrm{CH}_{2}\right), 1.43-1.33\left(\mathrm{~m}, 2 \mathrm{H},-\mathrm{CH}_{2}\right), 0.86(\mathrm{t}, J=7.4 \mathrm{~Hz}$, $3 \mathrm{H},-\mathrm{CH}_{3}$ ). Yield: $88.8 \%$.

\section{PEG0.75k-GL2-IMDQ}

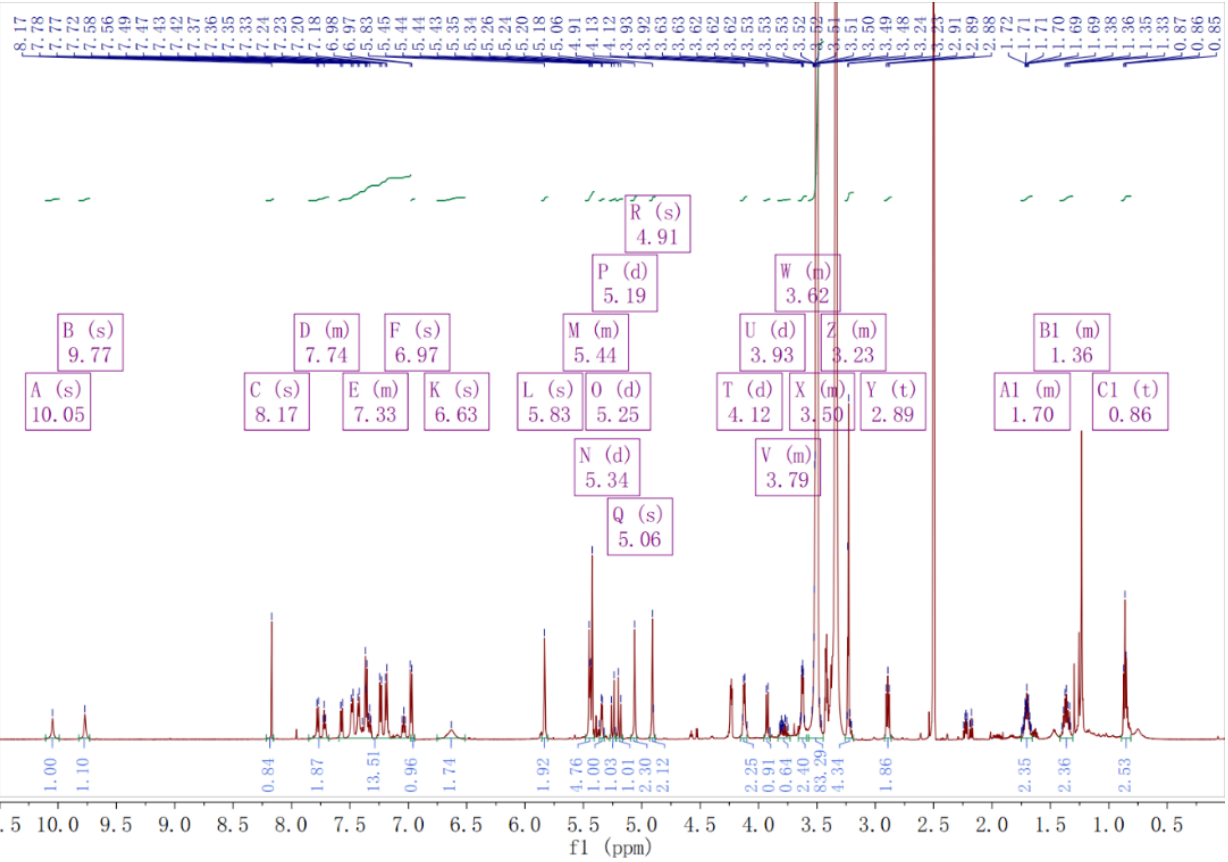


${ }^{1} \mathrm{H}$ NMR (600 MHz, DMSO- $\left.d_{6}\right) \delta 10.05$ (s, 1H, Ar-NH), 9.77 (s, $\left.1 \mathrm{H}, \mathrm{Ar}-\mathrm{NH}\right), 8.17$ (s, $1 \mathrm{H}$, triazyl), $7.85-7.68(\mathrm{~m}, 2 \mathrm{H}, \mathrm{Ar}), 7.59-6.98(\mathrm{~m}, 14 \mathrm{H}, \mathrm{Ar}), 6.97(\mathrm{~s}, 1 \mathrm{H}, \mathrm{COONH}), 6.63(\mathrm{~s}$, $\left.2 \mathrm{H},-\mathrm{NH}_{2}\right), 5.83\left(\mathrm{~s}, 2 \mathrm{H}, \mathrm{Ar}_{-} \mathrm{CH}_{2}-\mathrm{N}\right), 5.48-5.41(\mathrm{~m}, 3 \mathrm{H}$, Glu-OH, Glu 1-H), $5.34(\mathrm{~d}, J=$ $5.1 \mathrm{~Hz}, 1 \mathrm{H}, \mathrm{Glu}-\mathrm{OH}), 5.06\left(\mathrm{~s}, 2 \mathrm{H}, \mathrm{Ar}-\mathrm{CH}_{2}\right), 4.91\left(\mathrm{~s}, 2 \mathrm{H}, \mathrm{Ar}_{-} \mathrm{CH}_{2}\right), 4.12(\mathrm{~d}, J=6.2 \mathrm{~Hz}, 2 \mathrm{H}$, Ar- $\left.\mathrm{CH}_{2}-\mathrm{NH}\right), 3.93\left(\mathrm{~d}, J=9.3 \mathrm{~Hz}, 1 \mathrm{H}\right.$, Glu 5-H), $3.83-3.73\left(\mathrm{~m}, 2 \mathrm{H}, \mathrm{CH}_{2}\right.$-triazyl), $3.57-$ $3.45\left(\mathrm{~m}, 60 \mathrm{H},\left(\mathrm{O}-\mathrm{CH}_{2}-\mathrm{CH}_{2}-\right)_{15}\right), 3.26-3.19\left(\mathrm{~m}, 6 \mathrm{H}\right.$, Glu 2,3,4-H, $\left.-\mathrm{CH}_{3}\right), 2.89(\mathrm{t}, J=7.8$ $\left.\mathrm{Hz}, 2 \mathrm{H},-\mathrm{CH}_{2}\right), 1.75-1.66\left(\mathrm{~m}, 2 \mathrm{H},-\mathrm{CH}_{2}\right), 1.42-1.31\left(\mathrm{~m}, 2 \mathrm{H},-\mathrm{CH}_{2}\right), 0.86(\mathrm{t}, J=6.8 \mathrm{~Hz}$, $\left.3 \mathrm{H},-\mathrm{CH}_{3}\right)$. Yield: $21.4 \%$.

\section{PEG5k-IMDQ}

$0.9 \mathrm{mmol}$ of PEG5k-COOH was dissolved in $2.6 \mathrm{~mL}$ DCM and to this solution $3.33 \mathrm{mg}$ $(1.5 \mathrm{mmol})$ of EDC $\cdot \mathrm{HCl}, 2 \mathrm{mg}(1.5 \mathrm{mmol})$ of NHS and $2.42 \mu \mathrm{L}(1.5 \mathrm{mmol})$ of TEA were added. The mixture was stirred for 2 hours and $5 \mathrm{mg}(1 \mathrm{mmol})$ of IMDQ and $3.2 \mu \mathrm{L}(2$ mmol) of TEA in $100 \mu \mathrm{L}$ of DMF were added in the PEG solution. The reaction was kept for 24 hours under stirring at room temperature and the product was processed by dialysis. Yield: $40 \%$.

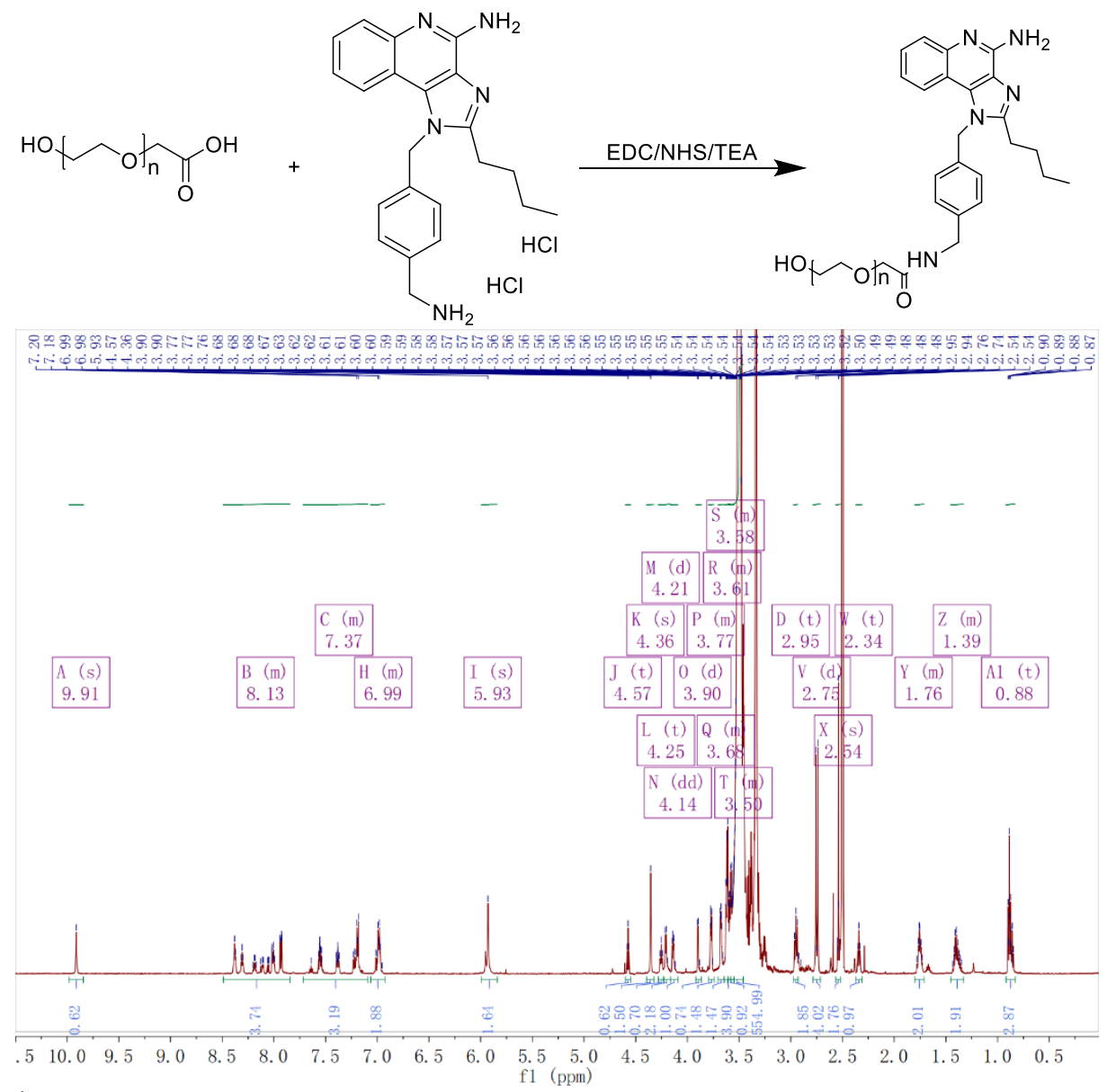

${ }^{1} \mathrm{H}$ NMR (600 MHz, DMSO-d $\left.d_{6}\right) \delta 9.91$ (s, 1H, -NH), $8.49-7.84$ (m, 4H, Ar), $7.72-7.09$ (m, 4H, Ar), $7.06-6.93$ (m, 2H, -NH $), 5.93\left(\mathrm{~s}, 2 \mathrm{H}, \mathrm{Ar}_{-} \mathrm{CH}_{2}-\mathrm{N}\right), 4.57$ (t, $J=5.5 \mathrm{~Hz}, 1 \mathrm{H},-$ $\mathrm{OH}), 3.80-3.74\left(\mathrm{~m}, 2 \mathrm{H}, \mathrm{Ar}-\mathrm{CH}_{2}-\mathrm{NH}\right), 3.70-3.65\left(\mathrm{~m}, 2 \mathrm{H}, \mathrm{O}_{-} \mathrm{CH}_{2}-\mathrm{O}\right), 3.58-3.46(\mathrm{~m}$, $\left.448 \mathrm{H},\left(\mathrm{O}-\mathrm{CH}_{2}-\mathrm{CH}_{2}-\right)_{112}\right), 2.95\left(\mathrm{t}, J=7.8 \mathrm{~Hz}, 2 \mathrm{H},-\mathrm{CH}_{2}\right), 1.80-1.71\left(\mathrm{~m}, 2 \mathrm{H},-\mathrm{CH}_{2}\right), 1.45-$ $1.33\left(\mathrm{~m}, 2 \mathrm{H},-\mathrm{CH}_{2}\right), 0.88\left(\mathrm{t}, J=6.8 \mathrm{~Hz}, 3 \mathrm{H},-\mathrm{CH}_{3}\right)$. 


\section{Preparation and characterizations of vesicles}

The vesicles were prepared by a nano-precipitation method. Briefly, the polymer was dissolved in THF at $1 \mathrm{mg} / \mathrm{mL}$, which was added dropwise to de-ionized water $(\mathrm{THF} /$ water $=1 / 1, \mathrm{v} / \mathrm{v})$ in a sonication bath in 10 minutes. Afterwards, the mixture was kept at room temperature for 24 hours to allow for evaporation of the organic solvent and the formulation was filtered via 0.45 micrometer membrane. Samples based on the other PEGIMDQ conjugates (PEG5k-IMDQ, PEG5k-GL1/3-IMDQ, PEG2/0.75k-GL2-IMDQ) were formulated with the same protocol. The size of the samples was measured by dynamic light scattering using Malvern Zetasizer. The morphology of the nanoparticles was analyzed by a transmission electron microscope (TEM) LEO 906 (Carl Zeiss, Oberkochen, Germany).

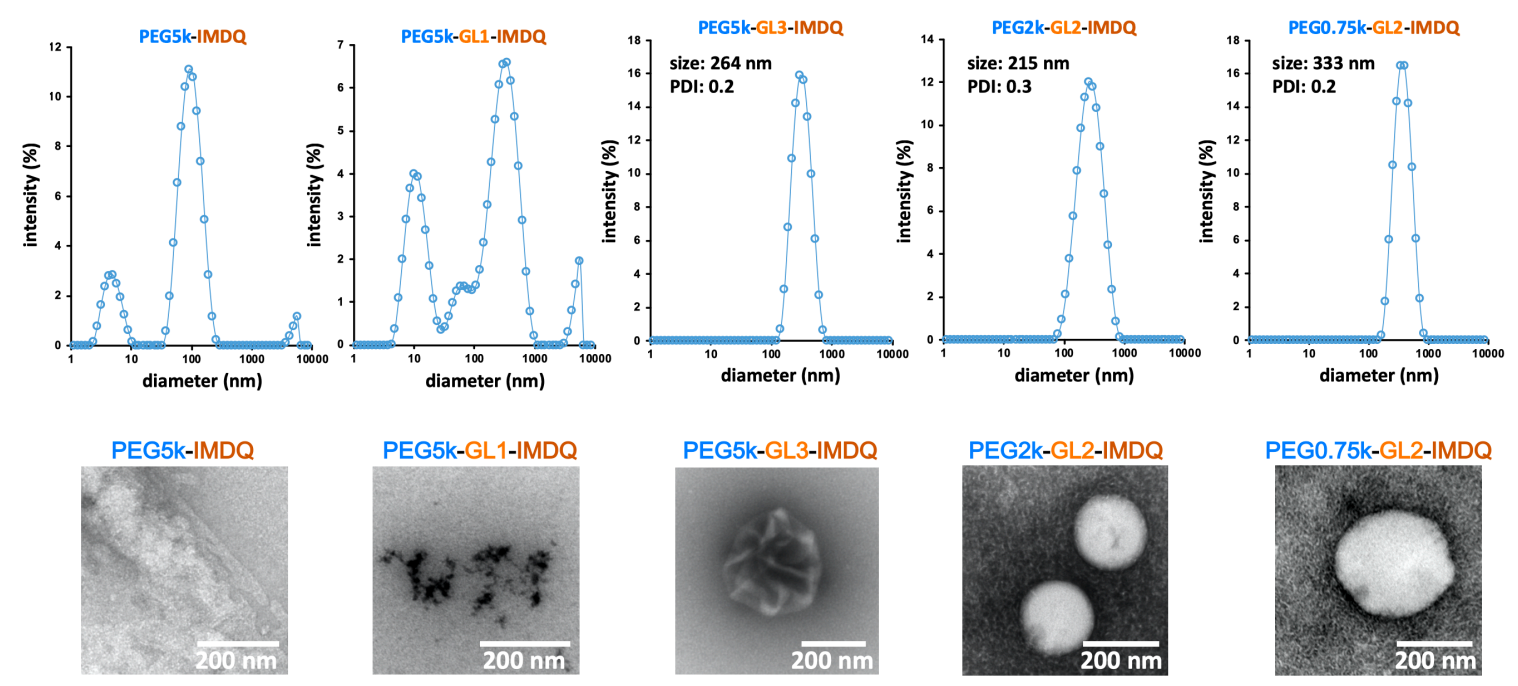

Figure S1. Size distribution by measured DLS and TEM images.

\section{Stability of nanoparticles based on PEG5/2/0.75k-GL2-IMDQ}

To assess the stability of the nanoparticles based on PEG5/2/0.75k-GL2-IMDQ, the nanoparticles were diluted 2 times in PBS 7.4 and incubated at $37^{\circ} \mathrm{C}$. At pre-set time points, the samples were analyzed by DLS and the size and PDI were recorded.
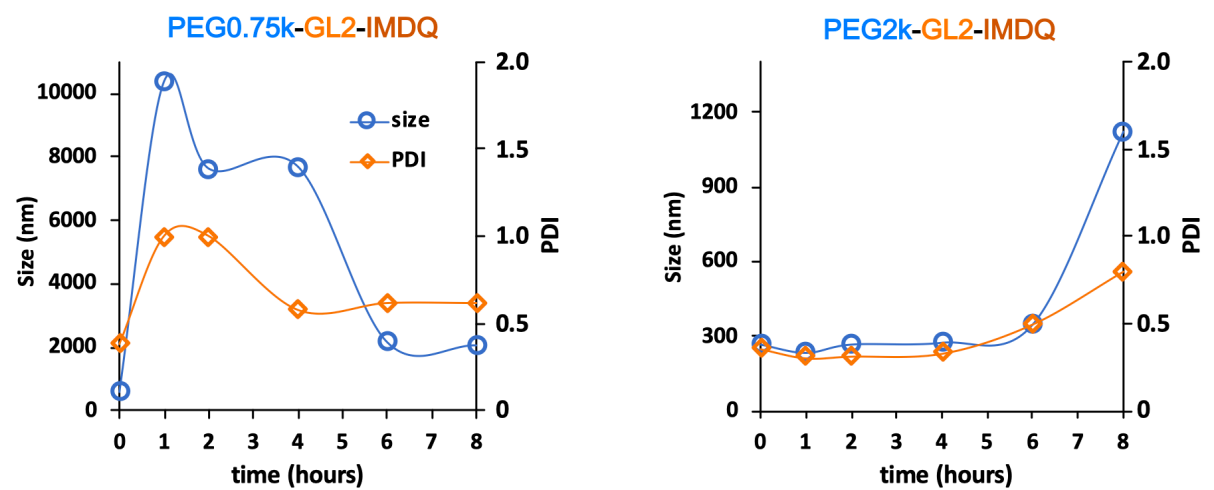

Figure S2. Stability of nanoparticles based on PEG2/0.75k-GL2-IMDQ in PBS at $37^{\circ} \mathrm{C}$. 


\section{Enzymatic degradation of vesicles}

To mimic enzymatic degradation of vesicles in endosomes, the formulation was diluted in PBS at $\mathrm{pH} 5.0$ containing $200 \mu \mathrm{g} / \mathrm{mL}$ esterase and $50 \mu \mathrm{g} / \mathrm{ml} \beta$-GUS at $37{ }^{\circ} \mathrm{C} .50 \mu \mathrm{L}$ of samples were taken at different time points and the concentration of free IMDQ was analyzed by high performance liquid chromatography (HPLC) with a standard curve of IMDQ. The samples were analyzed with a $\mathrm{C} 8$ column and a gradient elution method $\left(5 \% \mathrm{ACN} / 95 \% \mathrm{H}_{2} \mathrm{O}+0.1 \%\right.$ TFA to $95 \% \mathrm{ACN} / 5 \% \mathrm{H}_{2} \mathrm{O}+0.1 \%$ TFA in 10 minutes). The flow rate was $1 \mathrm{~mL} / \mathrm{min}$ and the detection wavelength was $254 \mathrm{~nm}$.

\section{In vitro RAW Blue assay}

The in vitro immunoactivation of the vesicles and control samples were assessed by the RAW Blue assay. The RAW Blue macrophages were cultured in DMEM medium supplemented with $10 \%$ heat-inactivated fetal bovine serum, $1 \%$ penicillin/streptomycin, $2 \mathrm{mM}$ L-glutamine, $1 \mathrm{mM}$ sodium pyruvate and $0.01 \%$ Zeocin in a 96-well round bottom plate with $0.5 \times 10^{6}$ cells $/ \mathrm{mL}$. After overnight incubation, the vesicles, PEG5k-IMDQ, GL2IMDQ and native IMDQ were added in the wells. PBS was used as the negative control. After incubation for 24, 48 and 72 hours, $50 \mu \mathrm{L}$ of the supernatant was taken and mixed with $150 \mu \mathrm{L}$ Quanti blue solution in 96-well flat bottom plates. Afterwards, the plates were incubated at $37{ }^{\circ} \mathrm{C}$ for 3 to 6 hours and absorbance was measured by a plate reader at 620 $655 \mathrm{~nm}$.

\section{Cellular uptake of $\mathrm{Cy3}$}

Cyanine3 dicarboxylic acid was hydrophobically modified with benzylalcohol and dissolved at $1 \mathrm{mg} / \mathrm{mL}$ in ethanol. From this solution $10 \mu \mathrm{L}$ was added to $1 \mathrm{~mL}$ of PEG5kGL2-IMDQ or PEG5k-IMDQ followed by filtration through a $450 \mathrm{~nm}$ filter to remove non-encapsulated dye. Cellular uptake of the dye was measured by confocal microscopy (Figure S3) by pulsing DC2.4 (immortalized) mouse dendritic cells with the respective filtered solutions.

\section{PEG5k-GL2-IMDQ}

\section{PEG5k-IMDQ}
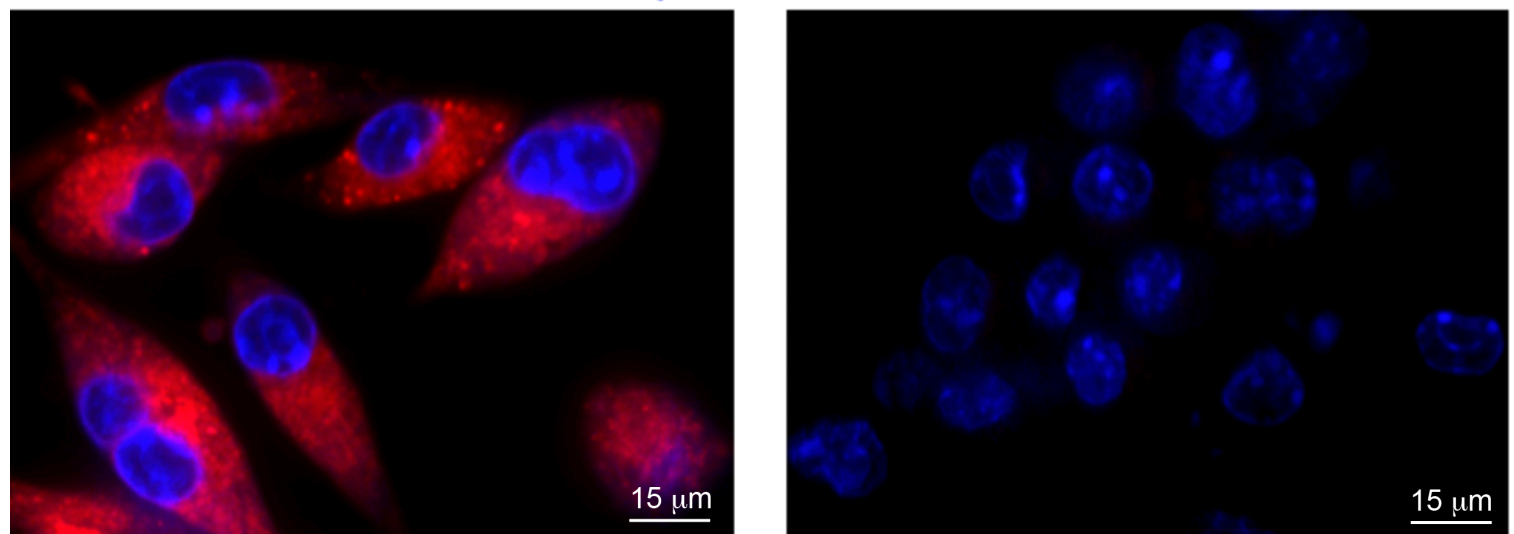

Figure S3. Cellular uptake of hydrophobically-modified Cyanine3 (red fluorescence) mixed with PEG5k-GL2-IMDQ vesicles or PEG5k-IMDQ. DAPI (blue fluorescence) was used to stain the nuclei. 


\section{In vivo immunoactivation in luciferase reporter mice}

In vivo immunoactivation of the vesicles was performed in luciferase reporter mice (IFN $\beta+/ \Delta \beta$-luc) with a BALB/c background. The mice were in-house bred. Heterozygous mice of 7-9 weeks old were included in the study. Each group of mice $(n=3)$ were housed in ventilated cages and given ad libitum access to food and water. $20 \mu \mathrm{L}$ of vesicles, PEG5k-IMDQ and IMDQ solution containing $100 \mu \mathrm{g} / \mathrm{mL}$ IMDQ were injected subcutaneously in the footpad of the mice. Luminescence imaging of the mice at different time points was recorded using an IVIS Lumina II imaging system. The mice were injected subcutaneously with $200 \mu \mathrm{L}$ D-luciferin and after 12 minutes luminescence imaging was performed. Luminescence intensity at the local injection site (the footpad) and the draining lymph node was quantified using the Living Image Software 4.5.
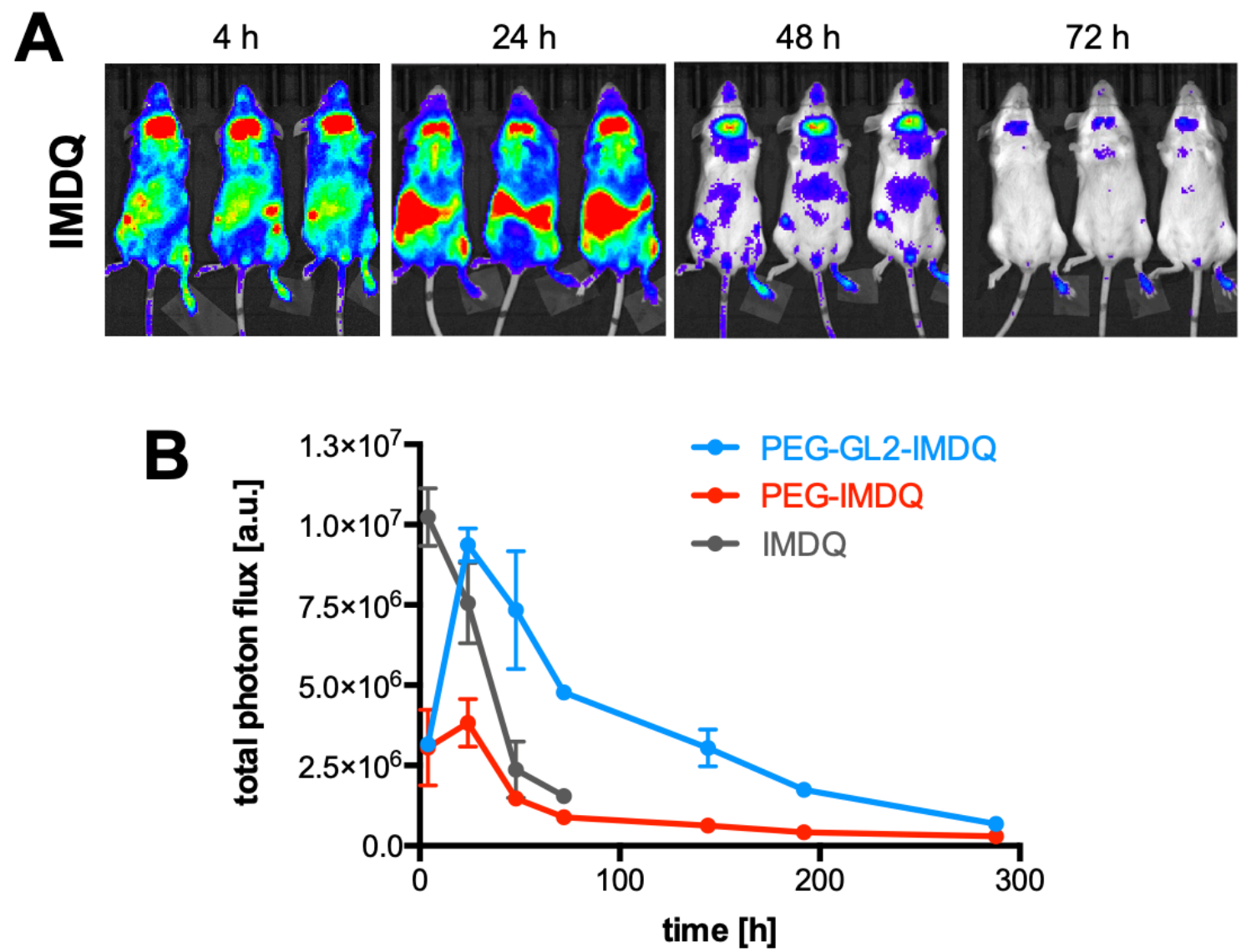

Figure S4. (A) IVIS imaging of IFN $\beta+/ \Delta \beta$-luc reporter mice upon subcutaneous injection of native soluble IMDQ into the footpad. (B) Fluorescence signal detected at the local injection site and draining $\mathrm{LN}$ of the IFN $\beta+/ \Delta \beta$-luc reporter mice. $(\mathrm{n}=3)$

\section{In vivo dendritic cell recruitment and maturation}

$20 \mu \mathrm{L}$ of sample was injected into the footpad of mice with a BALB/c background $(n=3)$. IMDQ concentrations were equalized in all samples relative to the concentration in 100 $\mu \mathrm{g} / \mathrm{mL}$. 24 hours post injection, mice were sacrificed and popliteal lymph nodes where isolated for flow cytometry. A single cell suspension was prepared from the dissected popliteal lymph nodes for analysis by flow cytometry. Isolated lymph nodes were collected in ice-cold PBS, smashed through $70 \mu \mathrm{m}$ cell strainers, washed with PBS and stained for 
30 minutes at $4^{\circ} \mathrm{C}$ with DAPI and with the following primary labeled monoclonal antibodies: CD3, CD19, CD11c, MHCII, CD40, CD80, CD86. 123count eBeads were added prior to flow cytometry aquisition (BD FACS Aria) to allow for counting relative cell numbers. Analyses were done using the FlowJo software package. After elimiation of debris, dead cells (DAPI-positive) and multiplets, DCs were selected as being negative in CD3 and CD19, and postive in MHCII and CD11c.

\section{References:}

[1] Shukla, N. M.; Malladi, S. S.; Mutz, C. A.; Balakrishna, R.; David, S. A. Structure-Activity Relationships in Human Toll-like Receptor 7-Active Imidazoquinoline Analogues. J. Med. Chem. 2010,53 (11), 4450-4465. [2] Lienenklaus, S.; Cornitescu, M.; Ziętara, N.; Łyszkiewicz, M.; Gekara, N.; Jabłońska, J.; Edenhofer, F.; Rajewsky, K.; Bruder, D.; Hafner, M.; Staeheli, P.; Weiss, S. Novel Reporter Mouse Reveals Constitutive and Inflammatory Expression of IFN- $\beta$ In Vivo. J. Immunol. 2009, 183 (5), 3229-3236.

[3] Bollenback, G. N.; Long, J. W.; Benjamin, D. G.; Lindquist, J. A. The Synthesis of Aryl-Dglucopyranosiduronic Acids. J. Am. Chem. Soc. 1955, 77, 3310-3315.

[4] Bosco, M.; Rat, S.; Dupre, N.; Hasenknopf, B.; Lacote, E.; Malacria, M.; Rmy, P.; Kovensky, J.; Thorimbert, S.; Wadouachi, A. Lewis-Acidic Polyoxometalates as Reusable Catalysts for the Synthesis of Glucuronic Acid Esters under Microwave Irradiation. ChemSusChem. 2010, 3, 1249 - 1252

[5] Groot, F. M. H. D.; Loos, W. J.; Koekkoek, R.; Berkom, L. W. A. V.; G. F. Busscher, G. F.; Seelen, A. E.; Albrecht, C.; Bruijn, P. D.; Scheeren, H. W. Elongated Multiple Electronic Cascade and Cyclization Spacer Systems in Activatible Anticancer Prodrugs for Enhanced Drug Release. J. Org. Chem. 2001, 66 (26), 8815-8830 